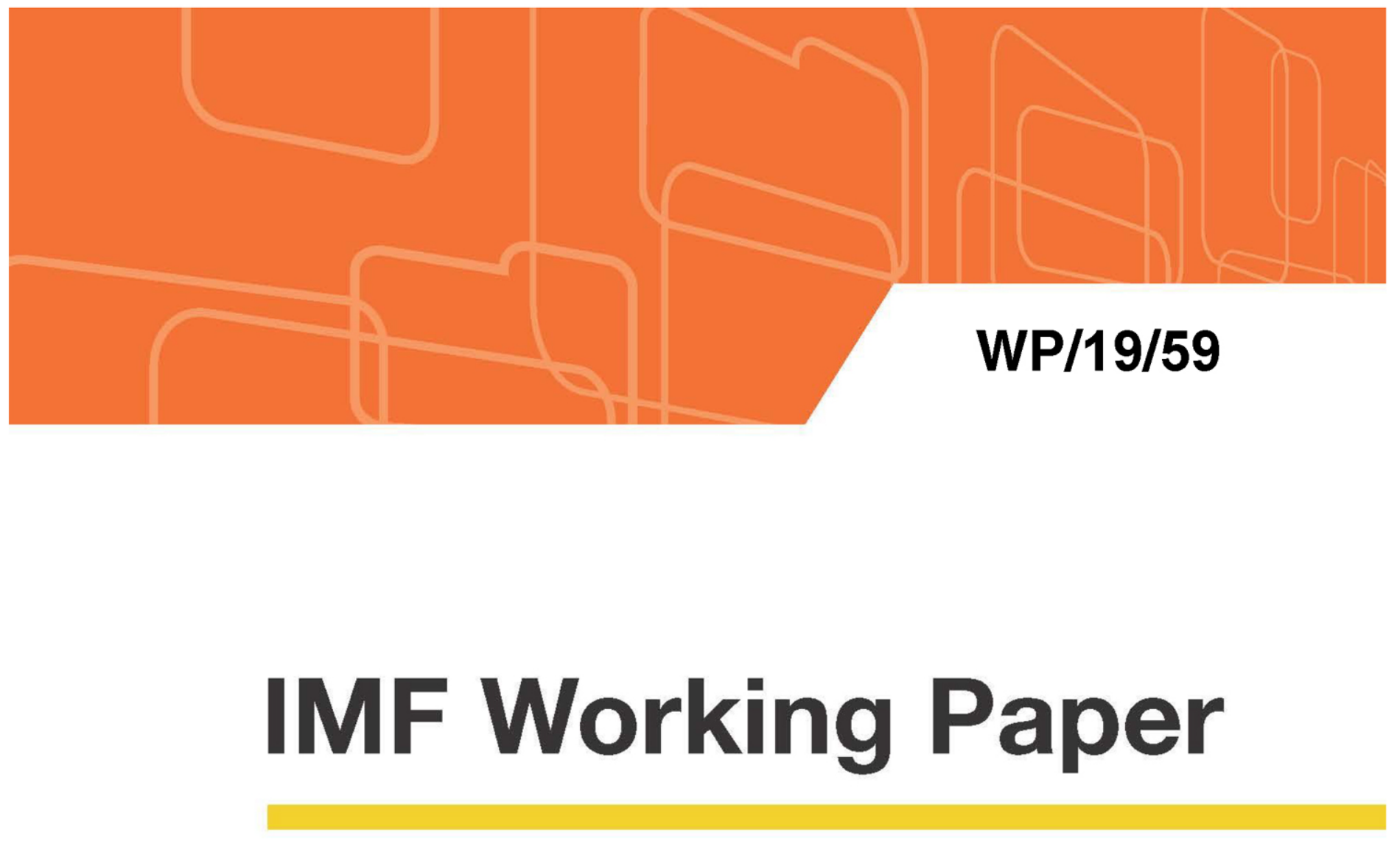

\title{
Assessing House Prices with Prudential and Valuation Measures
}

By Michal Andrle and Miroslav Plašil

IMF Working Papers describe research in progress by the author(s) and are published to elicit comments and to encourage debate. The views expressed in IMF Working Papers are those of the author(s) and do not necessarily represent the views of the IMF, its Executive Board, or IMF management.

$$
\text { I N T E R N A T I O N A L M O N E T A R Y F U N D }
$$




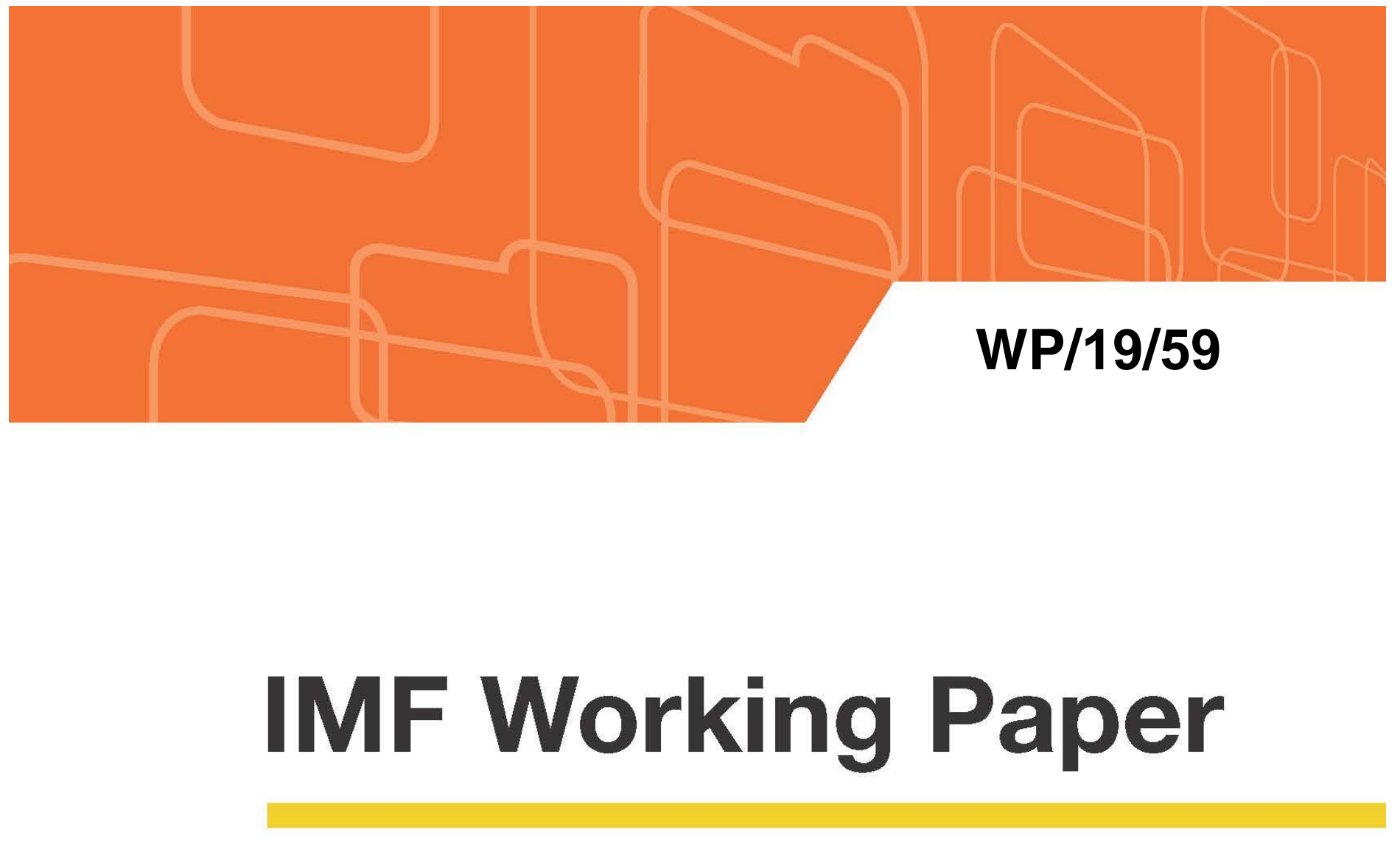

\section{Assessing House Prices with Prudential and Valuation Measures}

By Michal Andrle and Miroslav Plašil

IMF Working Papers describe research in progress by the author(s) and are published to elicit comments and to encourage debate. The views expressed in IMF Working Papers are those of the author(s) and do not necessarily represent the views of the IMF, its Executive Board, or IMF management.

$$
\text { I N T E R N A T I O N A L M O N E T A R Y F U N D }
$$




\title{
IMF Working Paper
}

Research Department

\section{Assessing House Prices with Prudential and Valuation Measures \\ Prepared by Michal Andrle and Miroslav Plašil}

Authorized for distribution by Benjamin Hunt

March 2019

\section{IMF Working Papers describe research in progress by the author(s) and are published to elicit comments and to encourage debate. The views expressed in IMF Working Papers are those of the author(s) and do not necessarily represent the views of the IMF, its Executive Board, or IMF management.}

\begin{abstract}
In this paper we provide tools for assessing the house prices and housing valuation. We develop two approaches: (i) borrowing capacity approach, and (ii) intrinsic value approach. The borrowing capacity of households, together with their down payment, implies how much housing they can attain. In the intrinsic value approach, property value is viewed as a discounted present value of adjusted net rental income. Our approach does not involve a complex econometric model and only widely available data are used. The proposed indicators can guide households, financial markets and macroprudential authorities in their understanding of house prices development. To illustrate the concepts, we analyze the housing prices in the Czech Republic and assess the degree of market over-and undervaluation.

JEL Classification Numbers: G1, G12, E37

Keywords: house prices, borrowing capacity, present value, financial stability

Author's E-Mail Address: mandrle@,imf.org, miroslav.plasil@,cnb.cz The views expressed herein are those of the authors and should not be attributed to the Czech National Bank nor the International Monetary Fund, its Executive Board, or its management. We would like to thank Pavel Gertler, Benjamin Hunt, Cheng Hoon Lim, Zlatuše Komárková, Mika Kortelainen, Alasdair Scott, and participants at the Czech National Bank's seminar in July 2018 and participants at the IMF European Department and National Bank of Slovakia seminars in November 2018 for their comments and suggestions.
\end{abstract}


I. Introduction $\ldots \ldots \ldots \ldots \ldots$

II. Relationship to the Literature . . . . . . . . . . . . . . . . $\underline{6}$

III. The Borrowing Capacity Approach . . . . . . . . . . . . . . . $\underline{8}$

A. Static Borrowing Capacity $(\mathrm{SBC}) \ldots \ldots \ldots \ldots$

B. Dynamic Borrowing Capacity (DBC) .............. 11

IV. The Intrinsic-Value Approach . . . . . . . . . . . . . . . . . . . . 14

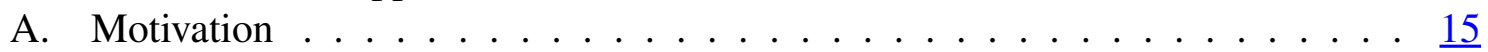

B. Implementation . . . . . . . . . . . . . . . . . 17

V. Application and Analysis: House Prices in Prague . . . . . . . . . . . . . . 20

A. Parameterization and Data Inputs . . . . . . . . . . . . . . $\underline{20}$

B. Borrowing-Capacity Approach ............... $\underline{23}$

C. Intrinsic-Value Approach . . . . . . . . . . . . . . 27

VI. Extensions and Further Analysis . . . . . . . . . . . . . . 30

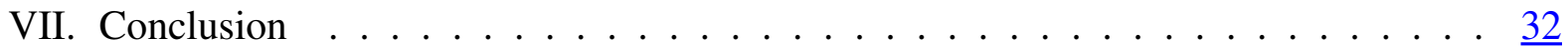

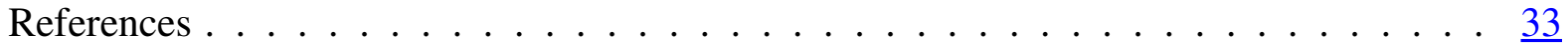
Appendices

A. Why We Do Not Use a Regression Model . . . . . . . . . . . . . . . $\underline{35}$

B. Building Prudential Scenarios and Counterfactuals with the SBC Approach . . . $\underline{38}$

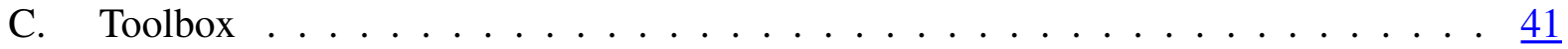

Tables

Figures

1. Prague: Housing Market Snapshot . . . . . . . . . . . . . . . . 21

2. Loan-Service-to-Income and Loan-to-Value Ratios for $2017 \mathrm{H} 2 \ldots \ldots$

3. Borrowing Capacity Approach: Results . . . . . . . . . . . . . . . 24

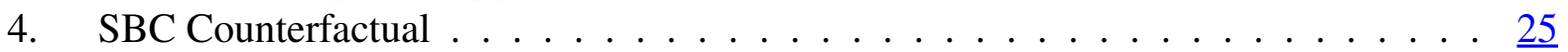

5. Income and Interest Rate Effects . . . . . . . . . . . . . . . . . . . 26

6. Sensitivity Analysis with Respect to $\alpha \ldots \ldots \ldots \ldots \ldots$

7. Average Intrinsic Value vs. Observed Prices . . . . . . . . . . . . . . . . . 28

8. Price-to-Value Estimate for Prague Housing Prices . . . . . . . . . . . . . . 29

9. Effects of Over-Optimistic Income Expectations . . . . . . . . . . . . . . . 30

10. Prague: Completed Dwellings vs. Increase in Number of Households . . . . . . . $\underline{31}$ 
11. Co-Integration Estimates: Results . . . . . . . . . . . . . . . . . . . $\underline{37}$

12. Interactive Interface to the Toolbox . . . . . . . . . . . . . . . . 41 


\section{INTRODUCTION}

Is housing overvalued? This is a frequent question not only in policy or academic circles but often at family dinner tables too. The decision to buy a house is one of the most important decisions in most people's lives. In this paper, we provide practical tools for assessing house prices, both in terms of their overall level and growth rate dynamics. We develop simple-touse prudential and valuation indicators, that can guide households, financial markets, central banks, or macroprudential authorities in their understanding of house prices development.

We follow two related approaches: (i) borrowing capacity approach and (ii) intrinsic value approach. When analyzing households' borrowing capacity, we compute the house prices implied by the household maximum capacity to safely borrow from a bank, given their income, market interest rate, and their down payment. The idea is that the market participants (sellers and developers) know this borrowing capacity and match house prices with it - the more households will push themselves to borrow, the more they will need to pay for housing. Individual household may perceive house prices as given but they are not. When we pursue the 'intrinsic value' approach, we compute the net-present value of the property of the prospective owner-occupier household, given the current and expected market conditions.

The first approach, the borrowing-capacity approach, is mostly (macro)prudential, while the other, the intrinsic-value or investment approach, adds a true valuation dimension to the analysis. Both indicators are simple to calculate, available in real time, and suffer from no expost revisions due to their structural nature.

Our goal is neither to explain, forecast or simply 'fit' house prices. Instead, we derive the estimates of attainable or warranted house prices, given the current and expected economic development. Such estimates should provide an anchor to observed market prices and help assess if house prices are overvalued or not. Therefore, it is imperative that we analyze the actual price of housing in actual money terms, in units of local currency, not relying only on index numbers. We also make sure that observed house prices do not enter any part of the calculation of the warranted or attainable price, to avoid circular reasoning - the value of an asset cannot depend on its price.

One of the key characteristics of our approach is a complete lack of time-series or paneldata econometrics. For economists, it may be hard to resist the urge to formulate a regression model that 'explains' house prices. In our view, it pays off to fight that urge. Our approach is structural and all of the key inputs and parameters are easy to understand, calibrate, 
and change for sensitivity analysis purposes. Importantly, the underlying parameters do not change their values and signs with increase in sample size as it is often the case when regression models are applied. Our proposed indicators also do not require historical data to assess the current situation, making them suitable both for advanced and emerging economies, and are explicitly forward-looking so as to closely follow the principles of asset valuation.

To illustrate the use of our indicators, we analyze the house prices development in Prague, the capital of the Czech Republic. The house prices in the Czech Republic, and especially in Prague, have increased dramatically in the past few years, making house prices an important policy issue. At the same time, the short time series of fundamental indicators - some reliable ones starting only after 2004 - and the lack of multiple business cycles remain a challenge for more 'traditional' econometric approaches to house price evaluation. According to our analysis, the econometric estimates for the Czech Republic are unstable and not intuitive, which further supports the need for alternative approach.

While we primarily focus on the role of fundamentals, such as household income and mortgage interest rates, we are of course aware that supply-side issues, like zoning rules or lengthy process of securing building permits, can also be relevant drivers of house price dynamics. However, we believe that we provide a compelling case for focusing on fundamentals first. Housing can still be overvalued with respect to income and interest rates. There is a point where living in London, Prague, or Vancouver just does not pay off anymore.

Our analysis suggests that at the time of writing, house prices in Prague were on average overvalued with respect to economic fundamentals. However, the degree of overvaluation was smaller than in the year 2008, due to favorable developments in household income and low mortgage interest rates. Especially using the borrowing capacity approach, a sizable portion of the increase in attainable house prices can be attributed to a decline in mortgage rates, thus lowering the degree of overvaluation.

Of course, our empirical analysis is subject to some important limitations. It focuses only on averages, aggregated values and does not pinpoint certain segments of the market that can be much more overvalued. However, the analytical tools presented in this paper can be readily applied to more granular data, even to individual household or property, where the precision of the tools can increase. 


\section{RELATIONSHIP TO THE LiterATURE}

The literature on house-prices analysis is incredibly large and our goal is not to provide a comprehensive review. Our reading of the literature is that in most of the applied papers the authors estimate a regression model of house prices or use the historical averages of price-toincome or price-to-rent indexes to interpret current values. See the analysis of central banks or international institutions in Philiponnet and Turrini (2017) at the European Commission, Igan and Loungani (2012) and Geng (2018) at the IMF, ECB (2015), ECB (2011), OECD (2005), McCarthy and Peach (2004) at the New York Fed, or Warisse (2017) at the National Bank of Belgium, among many others.

The specification of time-series or panel-data models is usually more or less motivated by the theory that suggests that house prices should correspond to the net present value of rental income. The resulting co-integrating or error-correction regressions usually explain house price indices using household income, short- and long-term interest rate, stock of credit, various demographic and supply side factors, or various cyclical indicators and stock-market prices, see Igan and Loungani (2012) or Hejlová, Hlaváček, and Komárek (2017).

Other contributions to the literature investigate house prices within models where house prices feed back to the rest of the economy, either in a fully-fledged dynamic stochastic general equilibrium models (DSGE) or using structural vector autoregressive models (SVARs), which allows them to estimate structural shocks driving house prices. Interpreting house prices in terms of structural shocks is useful for counterfactual analysis. Often, the result is that house-

price fluctuations are driven by the 'housing preference' shocks or housing credit shocks that relax the borrowing constraints, see Iacoviello and Neri (2010) for instance. Both type of models can be quite complex and require strong assumptions to identify the structural shocks and significant effort to be used in real-time house-price assessment.

Often, analysts only rely on long-term averages of housing indicators. There are several reasons why relying mostly on long-range historical comparison of price-to-income ratios or on simple regression models may be problematic. The analysis of the ratios implicitly assumes, or hopes for, a mean reversion in the given ratio. However, with the significant downward trend in nominal mortgage rates, such mean-reversion is far from guaranteed and at least a structural model to gauge the contribution of interest rates is needed.

The analysis using regression equations requires abundant historical data over multiple cycles, otherwise the estimated coefficients may be — and often are- unstable and the valua- 
tion assessment is prone to large revisions, see the stability analysis of Hejlová, Hlaváček, and Komárek (2017) or our own analysis in the Appendix A. Further, if it happens that house prices are sometimes overvalued but rarely undervalued, a simple linear regression model, that by construction has residuals summing to zero, may bias the valuation assessment by adjusting the reduced-form intercept. Lastly, some models in the literature have poorly defined steady-state growth and are prone to over-fitting when many explanatory variables are included and proper cross-validation is omitted. A model that overfits only seemingly explains house prices dynamics and may underestimate the degree of over- and undervaluation within sample. These are issues that motivate us to search for a different solution. ${ }^{1}$

We depart from the literature on house prices assessment in several ways. In contrast to the approaches discussed above, we derive attainable house prices or the value of a representative real-estate property using economic fundamentals without the reference to observed prices. To do this, we rely on structural models and only later contrast their results with the observed house prices. This is to further support the notion that the value and the price of an asset are two different things which are not always equal.

Our borrowing-capacity approach is inspired by introspection and by mortgage calculators often used by prospective home buyers. Our investment-approach is closer to contributions which use the valuation approach to house prices, either through the rental yield with the user cost of housing, see Himmelberg, Mayer, and Sinai (2005) or Fox and Tulip (2014). However, we extend the analysis beyond static (steady-state) ratios. We venture a fully forwardlooking valuation in the spirit of Damodaran (2012) and create a realistic but tractable valuation model for the owner-occupier housing problem. The fascinating thing about our simple theoretical models is how closely they can match the observed level of house prices - the theory seems to work.

Our model predictions are explicitly made in money terms, in units of local currency. Although the implied house prices dynamics are independent of the measurement units, it is only the comparison of actual house price and the valuation that determines the degree of overvaluation. Normalized indexes, predominantly used in the literature, are simply not enough and may lead to exercise in 'unitless econometrics'. While measuring aggregate house prices is not trivial, see Silver (2012), the actual price of a typical property (in terms of quality and size) is normally comparable to typical household income and demands on a period-by-period basis. It is thus important to express the house prices in actual money-terms, otherwise house prices cannot be contrasted to valuation measures.

\footnotetext{
${ }^{1}$ We provide thorough discussion on these issues in the Appendix A.
} 


\section{The Borrowing Capacity Approach}

The borrowing capacity approach should sound familiar. Inspired by the behavior of prospective home buyers, it indicates how much housing households can attain. It derives the maximum size of the mortgage loan that a household can safely borrow, given their income level, market interest rates, and a share of household income to be allocated for the mortgage payments. We assume the average household is credit constrained. Together with their available down payment, the mortgage loan indicates how much housing the households can afford.

This simple calculation is the way many households determine the size of an attainable mortgage, using a simple calculator on the internet. We assume that each household will reach for the maximum housing they can afford given their income level, the market interest rates and their down payment. All that while respecting the limits on loan-to-value (LTV) and debtservice-to-income (DSTI) ratios set by the regulators. Available data for many countries, including the Czech Republic, show the distribution of LTV and DSTI ratios bunching around the prudential limits set by the authorities.

Borrowing capacity analysis is not a valuation approach but a prudential, liquidity-constrained approach. Its application can be particularly useful to macroprudential authorities for deeper exploration of house price dynamics, or as a tool for counterfactual scenario analysis, and a communication vehicle. Within a macroprudential context, an analogy can be made to road speed limits. Surely, a small violation of the speed limit rarely results in an accident, similarly as driving below the limit by no means guarantees full safety. Nevertheless, setting road speed limits represents a generally accepted prudential measure. Similarly, borrowing capacity approach provides a reasonable macroprudential level of house prices that are consistent with sustainable household borrowing, low mortgage delinquency, and resilient financial sector. Regular communication of such a metric and its transparency may help anchor expectations of relevant market participants (banks and households) about the future course of macroprudential policy.

We present three variants of the borrowing-capacity indicator, varying in the degree of how forward-looking they are. First, we derive the simple static formula for house price assessment and discuss the pros and cons of this approach relative to the more forward-looking ones. 


\section{A. Static Borrowing Capacity (SBC)}

(a) Formulation The household decides to allocate a portion $\alpha$ of its nominal disposable income, $Y_{t}$, to initial mortgage payments for its desired housing:

$$
A_{t}=\alpha \times Y_{t}
$$

Given the nominal net mortgage interest rate per month, $i_{t}^{m}$ and given the desired (or macroprudentially constrained) mortgage payment, $A_{t}$, the mortgage loan for $N$ years is given by the following expression:

$$
L_{t}=A_{t} \times\left[\frac{z_{t}\left(1-z_{t}^{N \times 12}\right)}{1-z_{t}}\right] \quad \text { where } \quad z_{t} \equiv \frac{1}{1+i_{t}^{m}} .
$$

The attainable mortgage loan, $L_{t}$, coupled with the available down payment, $D_{t}$, determines the amount of housing, $P H_{t}$ that the household can afford:

$$
P H_{t} \equiv P_{t}^{h} \times H_{t}=L_{t}+D_{t}
$$

where $P_{t}^{h}$ denotes house prices per quantity, $H_{t}$, in square meters or a square feet. ${ }^{2}$ We keep the quantity of housing constant in the whole analysis.

The remaining determinant of the house prices is the down payment, $D_{t}$. At an individual household level, $D_{t}$ is known and can be treated as exogenous. For more aggregate analysis we need to make other assumptions, linking the down payment either to the loan value or to the current or past incomes.

For the observed or maximum values of $\alpha$ and loan-to-value ratio, $\phi$, we can always rewrite the attainable housing value as $P_{t}^{h} \times H_{t}=L_{t} / \phi$, or:

$$
P_{t}^{h} \times H_{t}=\frac{1}{\phi}\left[\frac{z_{t}\left(1-z_{t}^{N \times 12}\right)}{1-z_{t}}\right] \times \alpha Y_{t}
$$

which is the fundamental formula for the borrowing capacity approach.

Given the assumption of credit-constrained households who on average borrow at, or close to, the maximum debt-service-to-income (DSTI) limit, $\alpha \leq \alpha_{\max }$, and the loan-to-value (LTV),

\footnotetext{
${ }^{2}$ Simply put, given their income the households can purchase a small but expensive, luxurious property or the opposite.
} 
$\phi=L_{t} /\left(P_{t}^{h} \times H_{t}\right) \leq \phi_{\max }$, we chose our baseline static borrowing capacity relationship by letting the down payment be aligned with the DSTI and LTV limits. These assumptions are consistent with the observed data, as explained in the application part of the paper.

(b) Discussion The SBC formula (4) is helpful for thinking about the sustainable level and growth rate of house prices. In an economy with constant nominal interest rates, stable leverage and constant share of mortgage payments on income for new borrowers, the priceto-income ratio is uniquely determined and the nominal house prices should grow at the same rate as nominal disposable income of households: $P H_{t}=\dot{Y}_{t}{ }^{3}$

The SBC formula is simple, but note the nonlinear relationship between house prices and interest rate - something most empirical studies fail to account for. The formula (4) implies that the non-linearity increases with the duration of the mortgage, $N$. Since the average duration of the mortgage loan usually exceeds 20 years, the size of non-linear impact can be quite pronounced and should not be ignored. Avoiding approximations is particularly relevant at the low levels of interest rates that have been observed in the last few years.

A period-by-period evolution of the static borrowing capacity constraint can be contrasted with house prices assuming that house prices are determined by the new borrowers (home buyers) in the current period. If the historical data or forecast of key drivers are available, historical assessment as well as the forecast of house prices implied by the fundamentals can readily be carried out.

While a simple and powerful concept, the borrowing capacity approach is static and expected changes in mortgage rates and household income are not reflected at all. This increases the sensitivity of the implied house prices to the current level of mortgage rates and can make prices more pro-cyclical than forward-looking valuation measures would.

The expected changes in household income and interest rates matter even from the prudential point of view. Future increase in interest rates can result in excessive debt-service burdens for households if household income growth is not sufficiently strong to cover the increase in the debt service. This is relevant for adjustable-rate mortgage (ARM) loans where the interest rate gets re-set after every $K$ periods. ${ }^{4}$ For this reason, we consider a dynamic borrowingcapacity approach in the next section.

\footnotetext{
${ }^{3}$ While there are plausible economic reasons why the share of income devoted on housing can increase with the increase in real income, this would be reflected in the change of parameter $\alpha$ and very likely would be gradual.

${ }^{4}$ Adjustable-Rate Mortgages are not mortgages with flexible floating interest rate. Typically, the mortgage duration is $N$ period, where after each $K$ periods, often two or five years, the mortgage interest rate can be changed.
} 
(c) Counterfactual Analysis and Effects of Prudential Regulation In principle, the SBC formula can help to gauge the effects of mortgage-rate changes on house prices or the priceto-income indicators, as well as the effects of changes in other key parameters: debt-serviceto-income ratio, $\alpha$, loan-to-value ratio, $\phi$, or changes in average duration of the loan, $N$.

However, some care must be taken when performing counterfactual simulations or an assessment of the effects of macroprudential regulation on credit-constrained households. The short-run and the long-run responses can vary markedly due to the different assumptions on what variables are considered being fixed or slow-moving in the short run and in the long run, see the Appendix B and Andrle and Plašil (2019) for more detail.

For instance, a naive implementation of the formula (4) would lead to a conclusion that enforcing a lower loan-to-value ratio, $\phi$ (lower leverage), would actually lead to higher attainable house prices. Of course, this is infeasible in the short run and the dynamics of the down payment needs to be considered. In a situation where the mortgage-payment-to-income ratio is at its regulatory maximum, $\alpha_{0}=\alpha_{\max }$, the loan-to-value ratio is at its maximum, $\phi_{0}=\phi_{\max }$, and the level of the down payment is predetermined at a pre-shock level, $D_{0}$, the implementation of a new lower loan-to-value ratio $\phi_{1}=L_{1} /\left(L_{1}+D_{0}\right)$ will lead to a new, lower loan, $L_{1} \leq L_{0}$, with a lower implied $\alpha_{1} \leq \alpha_{0}$ for given level of income, interest rates, and available funds for down payment. Over time, the household income and the available down payment will change, relaxing some of the constraints, and affect the dynamics of attainable house prices. Similar consideration must be made for other scenarios, such as a decline in mortgage lending rates, for instance.

Appendix B illustrates that we can always define $\kappa_{t}=D_{t} / Y_{t}$ and rewrite the borrowing constraint as $P_{t}^{h} \times H_{t}=\alpha f\left(z_{t}\right) Y_{t}+\kappa_{t} Y_{t}$. The key is to realize that the parameters $\alpha, \phi$, and $\kappa$ are related and that they all cannot be set independently.

\section{B. Dynamic Borrowing Capacity (DBC)}

The dynamic borrowing-capacity approach (DBC) extends the static borrowing-capacity approach as it seeks the maximum sustainable mortgage loan such that the risk of excessive debt-service burden in the future is avoided or at least lowered.

For adjustable-rate or floating-rate mortgages the dynamic borrowing-capacity approach seeks to find a new initial size of the loan and of the debt-service-to-income ratio, $\alpha_{\text {init }}$, with which the household's debt-service capacity should not exceed the targeted prudential thresh- 
old $\alpha_{\max }$ at any period in the future. Should the increase in expected household income not compensate for the expected increase in the mortgage rates, the initial size of loan must be appropriately lowered.

Note that the dynamic borrowing capacity is an asymmetric measure and will always be lower or equal to the static borrowing capacity, $L_{D B C} \leq L_{S B C}$. In a situation where the mortgage interest rates are expected to be lower than current interest rates and household income growing, households would still not be allowed to breach the limits set by the static borrowing capacity. Given the generally positive expected growth in nominal income, the dynamic borrowing capacity constraints kick in under rather extreme circumstances where the current level of mortgage rates can be considered unusually low.

We implement two types of the DBC: (i) baseline DBC and (ii) DBC with an 'offset account'. On top of the baseline DBC, the offset-account DBC considers an actual or hypothetical 'offset' deposit account where households deposit the difference between $\alpha_{t+k} \times Y_{t+k}$ and $\alpha_{\max } \times Y_{t+k}$ for $K$ periods. In period $K$ where the mortgage rate is re-negotiated, households can use the saved deposit and the interest proceeds to lower their debt and debt-service burden.

In practice, the construction of the DBC can be seen as an optimization problem. The goal is to find the amortization schedule that leads to a maximum affordable loan but does not violate the constraints implied by prudential threshold, $\alpha_{\max }$ in the current or any future period. ${ }^{5}$

Since the static borrowing capacity represents an upper bound for any DBC metric, optimal solution can easily be found by following these steps: use static borrowing capacity as a starting value to initiate the optimization. Using this value, calculate the amortization schedule that is consistent with the expected path of income growth, mortgage rates and adjustablerate scheme and check whether the schedule violates the debt service-to-income constraint in any period. If the constraint is violated, lower the amount of the affordable loan and check the compliance with prudential thresholds once again. Continue lowering the amount until an acceptable solution is found and put it equal to the DBC metric. ${ }^{6}$

\footnotetext{
${ }^{5}$ Finding the maximum loan for the baseline DBC and the offset-account DBC differs only in how amortization schedule is constructed. For the offset-account DBC annuities are further adjusted for the saved deposits and the interest proceeds.

${ }^{6}$ In practical applications, a simple grid search with reasonable scaling coefficients applied to static borrowing capacity can be used. A more computationally-involved alternative is to use traditional optimizers where the violation of constraints is heavily penalized.
} 
The dynamic borrowing capacity approach can be further adjusted along many other dimensions. For instance, there might be a distinction between the recommended initial debt-serviceto-income ratio, $\alpha$, and the maximum allowed one, $\alpha_{\text {max }}$. In this case, the DBC could allow a larger loan when there are reasonable expectations of mortgage rates to decline, for instance. 


\section{The Intrinsic-Value Approach}

The intrinsic-value approach views the value of an asset as a discounted net present value of the income stream that the asset provides. This approach equips analysts with an explicit valuation of the real-estate property, in a forward-looking manner. While this approach is often the theoretical motivation for empirical econometric work, it is rarely used in the literature per se to obtain the valuation.

In words of a legendary investor Ch. Munger: "Valuation is simple, but it is not easy". While conceptually straightforward, the intrinsic value approach crucially depends on expectations of household income, rents, or mortgage rates many years ahead and is thus more involved than the prudential borrowing capacity approach. Ideally, valuation is not just a number, it is a process.

Valuation is subjective, sensitive to perceived opportunity cost and the economic outlook. We believe that this is not a hindrance but an invitation to sensitivity and scenario analysis. Valuation is a 'life vest' for households, real-estate investors, and regulators to form views about the 'fundamental value' of real-estate assets. ${ }^{7}$

To provide a realistic valuation, we refine simplified theoretical models available in introductory finance textbooks, developed to yield intuitive closed-form formulas. While we do not arrive at a simple closed-form expression, all the computations presented below can easily be performed in a spread-sheet.

Right from the start a distinction should be made between professional investors and retail investors or owner-occupiers. A professional investor, a REIT or an investment company, has different opportunity cost due to their portfolio diversification, smaller transaction costs, better access to secured or unsecured credit than households, and crucially for our analysis, professional investors tend to stay leveraged indefinitely. We will assume that the retail investors plan to repay the mortgage loan in full, not staying leveraged indefinitely. To stabilize leverage, retail investors would need to borrow up as the value of the property increases in time to stabilize the leverage.

\footnotetext{
${ }^{7}$ The 'life vest' parable we borrow from Ashwat Damodaran thoughts on valuation. www.stern.nyu.edu/ damodar/pptfiles/eq/ValClosing.ppt
} 


\section{A. Motivation}

To motivate the actual measures, we start by assuming that the prospective owner-occupier can either purchase a property or keep renting the housing services, on a period-by-period basis. The situation where the household is equally-well off renting or buying a property helps pinning down the value of the asset.

\section{Renting:}

1. Invest available funds, $D_{t}$, with period return, $i_{t}^{e}$

2. Pay the rent $t$ for the use of rented housing services

\section{Buying:}

1. Use the available funds as a down payment, $D_{t}$, and borrow funds, $L_{t}$ at interest $i_{t}^{m}$, to buy a property for $P H_{t}=D_{t}+L_{t}$. Consistently with the SBC approach, we define the LTV ratio as $\phi \equiv L_{t} / P H_{t}$

2. Pay the mortgage payment, approximated by $i_{t}^{m} L_{t}$, deducting the interest-payment from the taxable income, at the marginal rate of $\tau$

3. Pay the maintenance cost and property taxes, $\left(\delta+\tau_{p}\right) P H_{t}$

4. Sell the property at the end of the period for an expected price, $P H_{t+1 \mid t}$

For households to be indifferent between renting and buying, both alternatives must yield identical financial flow, which gives rise to the no-arbitrage condition:

$$
P H_{t}=\text { rent }_{t}+\frac{1}{1+z_{t}} P H_{t+1 \mid t},
$$

with the discount rate given by the following composite of factors:

$$
\left(1+z_{t}\right) \equiv(1+\underbrace{\left[(1-\phi) i_{t}^{e}+\phi \times(1-\tau) i_{t}^{m}\right]}_{\text {cost of capital + tax shield }}+\delta+\tau_{p}) .
$$

Iterating the household problem forward, we arrive at a well-known principle (Himmelberg, Mayer, and Sinai (2005)) of equating the value of the real-estate asset with a discounted net 
present value of future rents:

$$
P H_{t}=\sum_{i=0}^{\infty} \frac{\text { rent }_{t+i \mid t}}{\prod_{j=0}^{i}\left(1+z_{t+j}\right)} \quad \text { and } \quad P H_{s s}=\frac{r e n t}{z-g n}=\frac{\alpha Y}{z-g n} .
$$

Here $P H_{s s}$ denotes the relationship between the house prices and the current value of the nominal rents in the long-run, where the components of the discount factor, $z$, are constant and the rental income grows at a steady-state nominal growth, $g n$. To link the rents with our previous analysis, we can assume the rents to be a portion of household income, $Y_{t}$.

Formulas (7) and (6) provide us with the list of the key factors that drive the valuation. In the long-run, the price-to-income ratio is driven by the relative values of the nominal growth of income and the effective net discount factor, $z$, whose key component are interest rates in the economy. In the long-run, the price-to-income ratio is not affected by the long-run inflation level. If the long-run interest rates in the economy decline together with the nominal growth of income, the price-to-income ratio need not to change at all.

The structure of the discount factor, $z$, is intuitive as well and its key component is the effective cost of funds. The effective interest rate is thus given by:

$$
\left[(1-\phi) i_{t}^{e}+\phi \times(1-\tau) i_{t}^{m}\right]
$$

It is vital to distinguish between the cost of debt, the mortgage rate, $i_{t}^{m}$, and the opportunity cost (cost of equity), $i_{t}^{e}$. The effective cost of debt is also lowered by the option to deduct the interest expense from taxable income - ceteris paribus, the option to deduct interest expense from taxes increases house prices. If we assume that $i^{e}>i^{m}$, in the simple formula, an increased leverage $\phi$ lowers the cost of capital and may push house prices up. ${ }^{8}$

These simple and intuitive formulas are not, however, suitable for the actual implementation. While they do distinguish between the cost of equity and the cost of debt, for instance, they assume a constant leverage and an infinitely-lived mortgage loan. The actual implementation changes these assumptions.

It may also be tempting to use the static (steady-state) version of the formula (7) with current values of the variables, $P H=\alpha Y_{t} /\left(z_{t}-g n_{t}\right)$ to analyze the house prices. This, however, would be gravely mistaken. First, the formula would assume that the current income, $Y_{t}$ grows every period at a rate $g n$. Second, the formula would increase sensitivity to cyclical fluctuations in the effective discount rate $z_{t}$, similarly to the static borrowing capacity, and ignore

\footnotetext{
${ }^{8}$ At retail level, it is unlikely that an increase in leverage also increases the opportunity cost, $i^{e}$, as would be the case for corporations.
} 
the long-run growth of income that could be lower than current income growth, especially in emerging economies. As we show below, the resulting valuation would then be excessively volatile.

\section{B. Implementation}

Our implementation of the house price valuation uses a multi-step net present value model to take into account the cyclicality of rents and income and the nature of adjustable mortgage rates.

We assume the mortgage loan duration is $N$ years and the mortgage interest rate can be reset every $K \leq N$ years. ${ }^{9}$ This assumption implies at least three different terms in the valuation formula which reflect distinct levels of mortgage payments throughout the lifetime of the real-estate property. From year 1 to year $K$ the mortgage payment is constant, reset to a new level from a year $K$. This repeats every $K$ years until the mortgage is fully repaid.

To simplify the notation we assume, with no loss of generality, that the mortgage rate in pe$\operatorname{riod} R \geq K$ already coincides with its long-run steady-state value and the mortgage payments are kept constant at their nominal level until the full repayment of the mortgage in period $N$. After period $N$ the net rental income is no longer adjusted for the mortgage payments and is growing at a constant nominal growth rate, gn. Such a specification is general. The frequency of the model is annual but all the mortgage computations are carried out at monthly frequency with annual totals used for the valuation.

The value of the property, $V_{t \mid t}$, is a present value of net rental income, discounted by the opportunity cost, $i^{e}$. The net rental income is composed of after-tax rental, $(1-\tau)$ rent $_{t+i \mid t}$, adjusted for the mortgage payments, mpay $_{t+i \mid t}$, and also corrected for the tax-deductible interest

\footnotetext{
${ }^{9}$ This implies no loss of generality. More frequent changes in interest rates (or ever floating rates) can be considered at the cost of heavier notation. A common value for $K$ is $K=5$ years.
} 
rate cost, $\tau \times$ intcost $_{t+i \mid t}$. The formula used for the valuation is thus:

$$
\begin{aligned}
V_{t \mid t} & =\sum_{i=0}^{K-1} \frac{(1-\tau) \text { rent }_{t+i \mid t}-\text { mpay }_{t+i \mid t}+\tau \times \text { intcost }_{t+i \mid t}}{\prod_{j=0}^{i}\left(1+i_{e, t+j \mid t}\right)} \\
& +\sum_{i=K}^{N-1} \frac{(1-\tau) \text { rent }_{t+i \mid t}-\text { mpay }_{t+i \mid t}+\tau \times \text { intcost }_{t+i \mid t}}{\prod_{j=0}^{i}\left(1+i_{e, t+j \mid t}\right)} \\
& +\frac{1}{\prod_{j=0}^{N}\left(1+i_{e, t+j \mid t}\right)} \frac{(1+g n) \times(1-\tau) \text { rent }_{t+N \mid t}}{i_{e}-g n} .
\end{aligned}
$$

The first part of the formula reflects the first $K$ years when the mortgage payment is constant at its initial nominal value, while the rental income grows with the economy, and the interest cost gradually shrink as the share of principal repayment in mpay $_{t+i \mid t}$ increases. The second part is analogous to the first part but with the mortgage payment now different due to the newly negotiated mortgage rate, with changes until it reaches its steady-state value. Finally, in the third part of the formula after $N$ years mortgage payments are absent as the mortgage debt is fully repaid. Also, the projected level of rental income, rent $t_{t+N \mid t}$ is further expected to growth at a constant rate, $g n$, and the formula is a standard expression for an infinite sum of a geometric series.

We further assume that the growth rate of nominal rental income is identical to growth of the household nominal disposable income, keeping the rent-to-income constant in the projection. If more information is available, especially in the first few years of analysis, this can and should be used for the analysis of course.

To make the framework fully operational we must solve a subtle but important valuation nuance that is rarely discussed in the literature or empirical research. To arrive at the property value, we need to choose a size of the initial mortgage loan such that the loan-to-value ratio complies with some prudential limit, say $L T V=\phi=80 \%$. This creates a joint problem, where the initial loan affects the valuation and the valuation affects the size of the loan.

Our assumption is that the investors choose the down payment and the size of the loan in a flexible way to set their LTV in terms of their valuation. Doing otherwise would be imprudent. To obtain the property value conformable with the LTV requirement, we put the initial size of the loan equal to that implied by the borrowing capacity of the household with the 
mortgage payment equal to the rental income. Since the observed prices do not enter the analysis, we then compute the loan-to-value with the newly obtained value of the property in an interactive way to solve the joint problem of valuation and desired loan amount. ${ }^{10}$

\footnotetext{
${ }^{10} \mathrm{We}$ create a fine grid of scaling coefficients for the size of the loan, compute multiple valuations, and choose the one that satisfies all the criteria, including the LTV criterion. For instance, (Damodaran, 2012, pp. 749) points to this issue: "it is worth bearing in mind that the [debt] ratios should be based on the value of the property rather than the funding needs... This, of course, creates circular reasoning since the cost of capital is necessary to estimate the value of the property in the first place." Our view is that while problem is self-referential it is a standard, solvable fixed-point problem and not circular reasoning.
} 


\section{Application and Analysis: House Prices in Prague}

We apply our prudential and valuation metrics to assess the house prices in Prague, the capital of the Czech Republic. The housing market in Prague has witnessed sizable price changes in 2007-2008 and in recent years and the key question is: Is housing in Prague overvalued?

Figure 1 depicts the development of average nominal household monthly income, mortgage interest rates, and average house prices in Prague for an average-sized apartment. ${ }^{11}$ It also depicts a sizable and abrupt increase in price-to-income ratio that calls for caution and analysis. What are the fundamental factors driving the increase? Are those mostly supply-side factors, declining mortgage rates, or increase in loan-to-value and debt-service-to-income ratios?

In our experience, applying simple time-series regression model to Czech housing market does not lead to satisfactory answers. The estimated coefficients are often at odds with theory (wrong signs) and they are unstable, which causes frequent revisions of view about overvaluation, see the Appendix A or in detailed analysis by Hejlová, Hlaváček, and Komárek (2017). The reasons for regression analysis to perform poorly are partly due to short timeseries data lacking many housing cycles and partly due to fundamentally ad-hoc nature of such analysis, as we discuss in the Appendix A.

\section{A. Parameterization and Data Inputs}

We focus on average Prague household. For their income, $Y_{t}$, we use the nominal disposable income per capita and scale it up by 30 percent to match the average wage in Prague with respect to the nation-wide average wage. We further scale the income by coefficient of 1.65 - this scaling corresponds to a relationship between the disposable income per capita and the household income reported for mortgage loan applications. ${ }^{12}$

For the initial debt-service-to-income ratio, $\alpha$, we consider the baseline value of $\alpha=35 \%$ but perform a sensitivity analysis with respect to other values. Keeping the housing expense share of on income around 1/3 is generally considered a good rule-of-thumb in most countries.

\footnotetext{
${ }^{11}$ In the Czech Republic the income measure in the mind of public is the monthly one, traditionally. We make sure that the corresponding annual totals are used where appropriate.

${ }^{12}$ The scaling factor essentially reflects two different phenomena. First, the higher declared income is partly due to a higher average number of applicants included in the documented income. Second, the income level of applicants stands above the nation-wide averages thus positive selection bias can be observed.
} 
Figure 1. Prague: Housing Market Snapshot
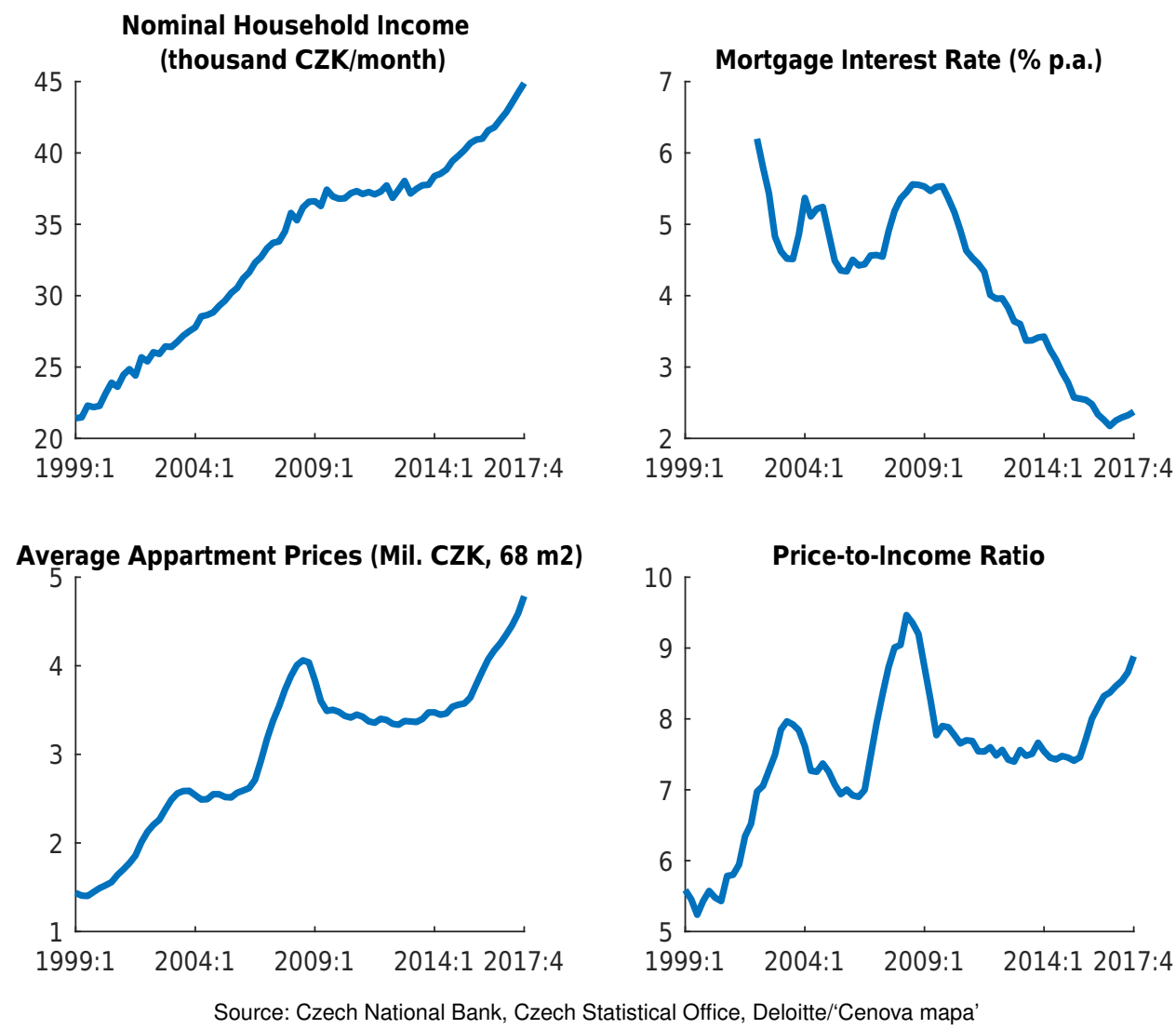

Stress-testing exercise carried out by Hejlová, Holub, and Plašil (2018) shows that sensitivity of Czech households to adverse economic shocks increases significantly for loans with $\alpha$ equal to or above $40 \%$. Further, we assume the loan-to-value ratio, $L T V$, to take a value of $\phi=80 \%$ in our computations. We believe these choices to be in line with the observed data, see Fig. 2 depicting the distribution of the loan-to-value and loan-service-to-income ratios in the Czech Republic for the second half of 2017. For the valuation approach, we assume that the gross rental income is a constant fraction of average household's disposable income. For compatibility with the borrowing-capacity approach, we set the rent at $35 \%$ of their income, but higher values are feasible as well.

The typical mortgage loan is assumed to have the duration of $N=25$ years, where the mortgage rate loan can be renegotiated every $K=5$ years. This assumption is relevant mostly for the dynamic borrowing-capacity computations and for the valuation approach. Consistently with the duration and fixed-rate horizon of the loan, we use the average mortgage interest rate for new five-year loans as available from the Czech National Bank (CNB). In the case of the 
Figure 2. Loan-Service-to-Income and Loan-to-Value Ratios for 2017H2

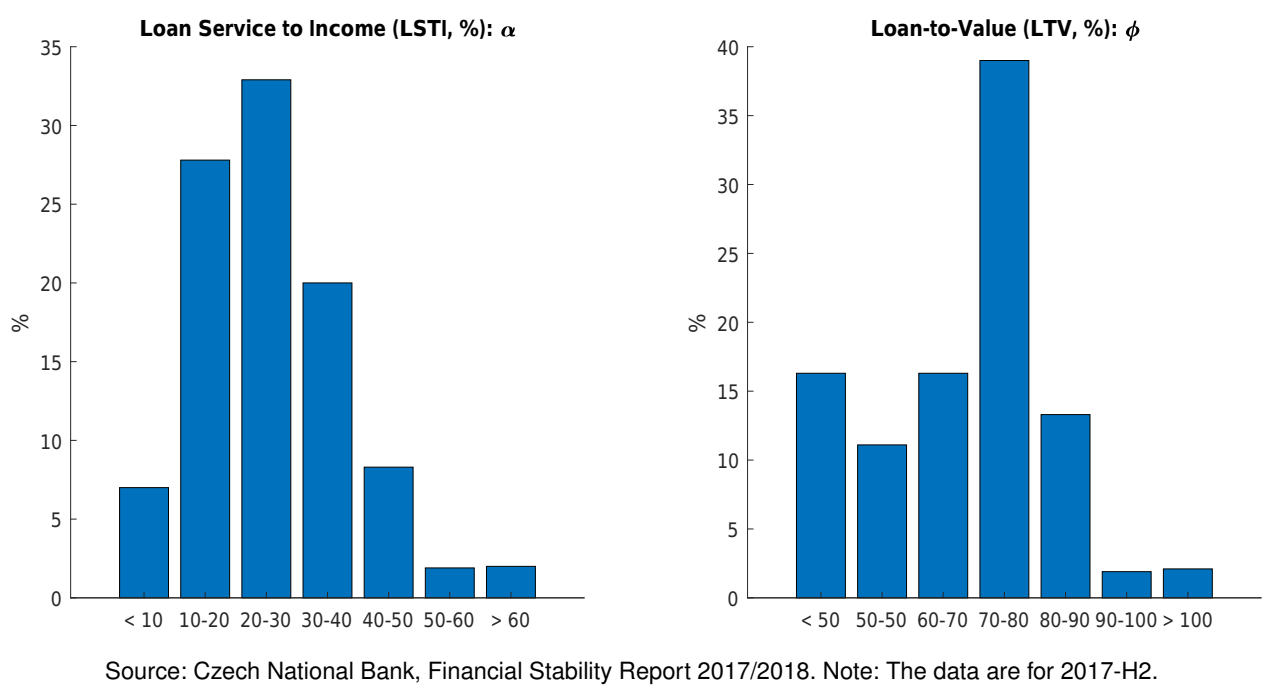

offset-deposit DBC calculation, we assume it yields an interest rate lower than the mortgage rate by 100 basis points (bps). ${ }^{13}$

For forward-looking measures, we assume that current household income will grow in line with the official forecast of the Czech National Bank (CNB) in the medium run and then converge to the long-run growth rate in an autoregressive way. The forecasts from the current forecasting system are only available as far back as 2008. Before this period, we project the growth of nominal household income as a first-order autoregressive process at annual frequency with the persistence of $\rho=0.25$ and a steady-state growth rate, $g n=4 \%$. For the steady-state mortgage interest rate we choose a value of $5 \%$, but a higher value is not unrealistic, given the $2 \%$ inflation target.

One of the crucial assumptions is the opportunity cost, $i^{e}$, which is not involved in the borrowing capacity consideration but is extremely important for valuation. Since the net rental income above is adjusted for the payout to debt holders (mortgage payments), the net rent is a flow to the owner (a flow to equity) the whole income stream is discounted by the opportunity cost of equity. For this paper, we choose the nominal opportunity cost of $6.5 \%{ }^{14}$ The

\footnotetext{
${ }^{13}$ For the years 2002-2003 where the mortgage interest rate data are not available, we use the yields of the 5Y government bonds to interpolate the mortgage loans using a simple regression relationship, given the very tight co-movement of the mortgage rates and government bonds yields before government bonds hit the effective zero or negative yield in the aftermath of the great financial crisis.

${ }^{14}$ While the valuation formula accommodate a time-varying opportunity cost, we use a constant value in the application. First, the dynamics of risk-free yields with the risk-premium on equity markets can result in a rather
} 
opportunity cost also reflects other factors relevant for the valuation. Note that we have not included maintenance cost in the user cost of capital. Under moderate assumptions the maintenance and depreciation can range from $1.5 \%$ to $2.5 \%$ of the house value, see Fox and Tulip (2014) or Himmelberg, Mayer, and Sinai (2005).

On the tax size, we assume the effective marginal tax rate of $\tau=15 \%$ but this assumption would ideally differ between the pure owner-occupier household and for a household with a rental property. We abstract from the real-estate transaction tax and we assume no real-estate property taxes, $\tau^{p}=0$ as the property taxation in the Czech Republic is negligible. ${ }^{15}$ Errors in these assumptions translate to the valuation level, not to valuation dynamics and would likely affect the consideration of the opportunity cost, $i^{e}$.

For both the borrowing-capacity approach and the valuation approach we need to choose the 'volume' of housing, $H_{t}$, and the relevant aggregate price per normalized quantity, $P_{t}^{h}$. Consistently with the existing data, we assume that the average apartment size is $68 \mathrm{~m}^{2}$. The price per squared-meter is determined as an average price of a new apartment in Prague sourced from the Czech Statistical Office (CZSO) data and the information from the company 'Cenova mapa' (price map) and Deloitte Czech Republic. ${ }^{16}$

The calibration assumptions are easy to alter for sensitivity analysis. We view the structural nature of all the parametric assumptions as one of the key benefits of our analysis over the reduced-form econometric approaches.

\section{B. Borrowing-Capacity Approach}

According to our estimated borrowing-capacity indicator of the average-income household in Prague, house prices were strongly overvalued in 2008 and seem overvalued in 2002-2004 and from 2017 onward, see Fig. 3.

The increase in housing attainable over time is due to the growth in households' nominal income and the gradual decline of mortgage interest rates. All other parameters of our simple

stable profile of the required yield. Second, given the long horizon of the analysis, the medium- and long-run value of the required yield clearly dominate the valuation. This holds for most NPV computations but is further aggravated by the interaction of discounting profile and net adjusted rent. In early years, the rent adjusted for mortgage payments is quite small.

${ }^{15}$ Unlike in the United States, where property taxes can range over 1 percent of the appraised value.

${ }^{16}$ All data are available from the authors, with the exception of the Czech National Bank's nominal income forecasts. Note that no forecasts are needed to obtain the baseline static borrowing capacity measure. 
Figure 3. Borrowing Capacity Approach: Results

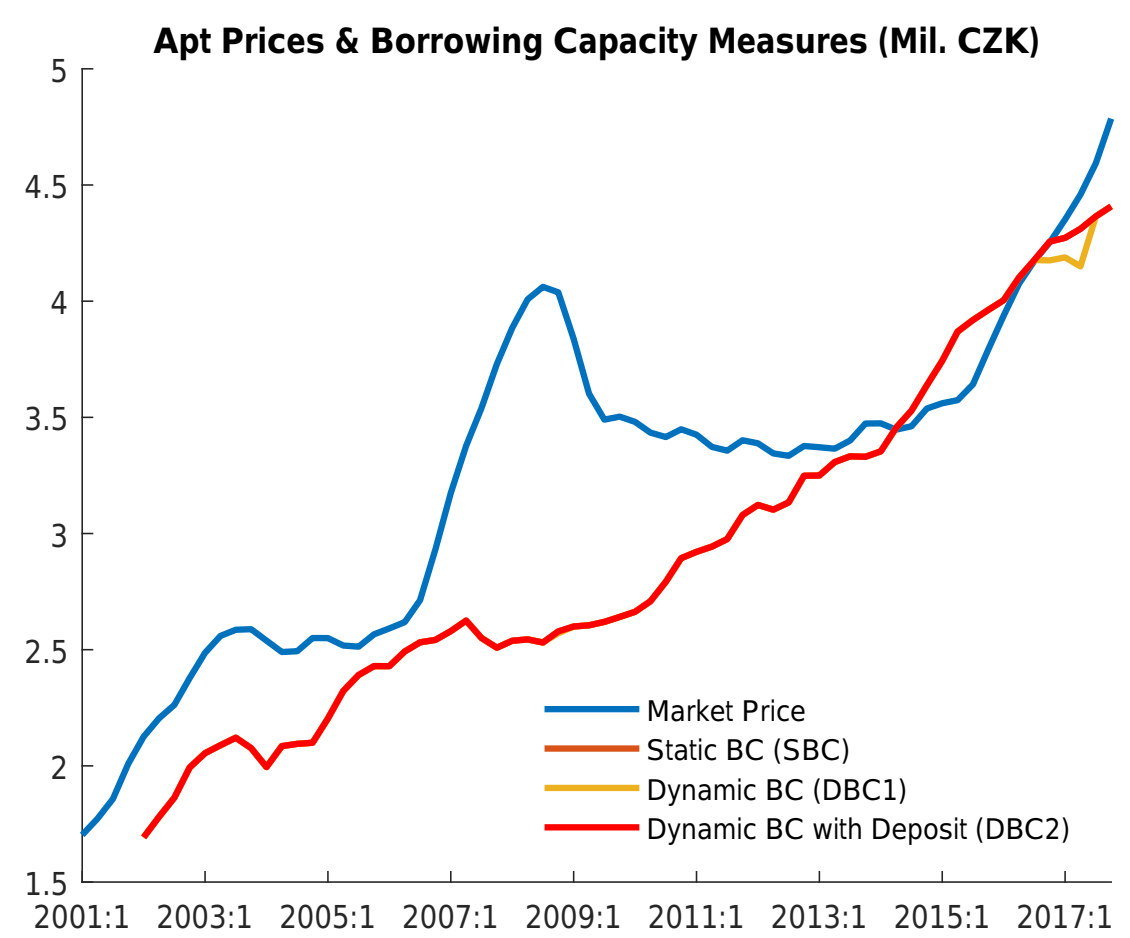

model are kept constant. A change in $\alpha$ or $L T V, \phi$, would change the level of apartment price but would not change its dynamics.

The increase in 'attainable' apartment price is substantial and arises because of Czech houeshold's robust income growth. A sizeable increase in attainable price using the borrowingcapacity approach is also due to decline in mortgage rates to unprecedented lows.

Most of the time the price implied by the dynamic borrowing capacity has not deviated from the baseline static borrowing-capacity approach, except for of a short-lived deviation at the end of 2016 and early 2017. This indicates that during that period the static borrowing capacity was unsustainable or close to unsustainable from the income and interest-rate forecast point of view.

One interesting aspect of our results is that the house prices implied by the borrowing-capacity relationship seem to define some sort of a 'lower support' for the observed house prices. The pricing gap thus is almost always either positive or zero, with a positive average value. This is in a stark contrast with what the results of a linear regression would be, where the pricing gap is restricted to be zero on average. Even with the elasticity constraints on the mortgage 
Figure 4. SBC Counterfactual

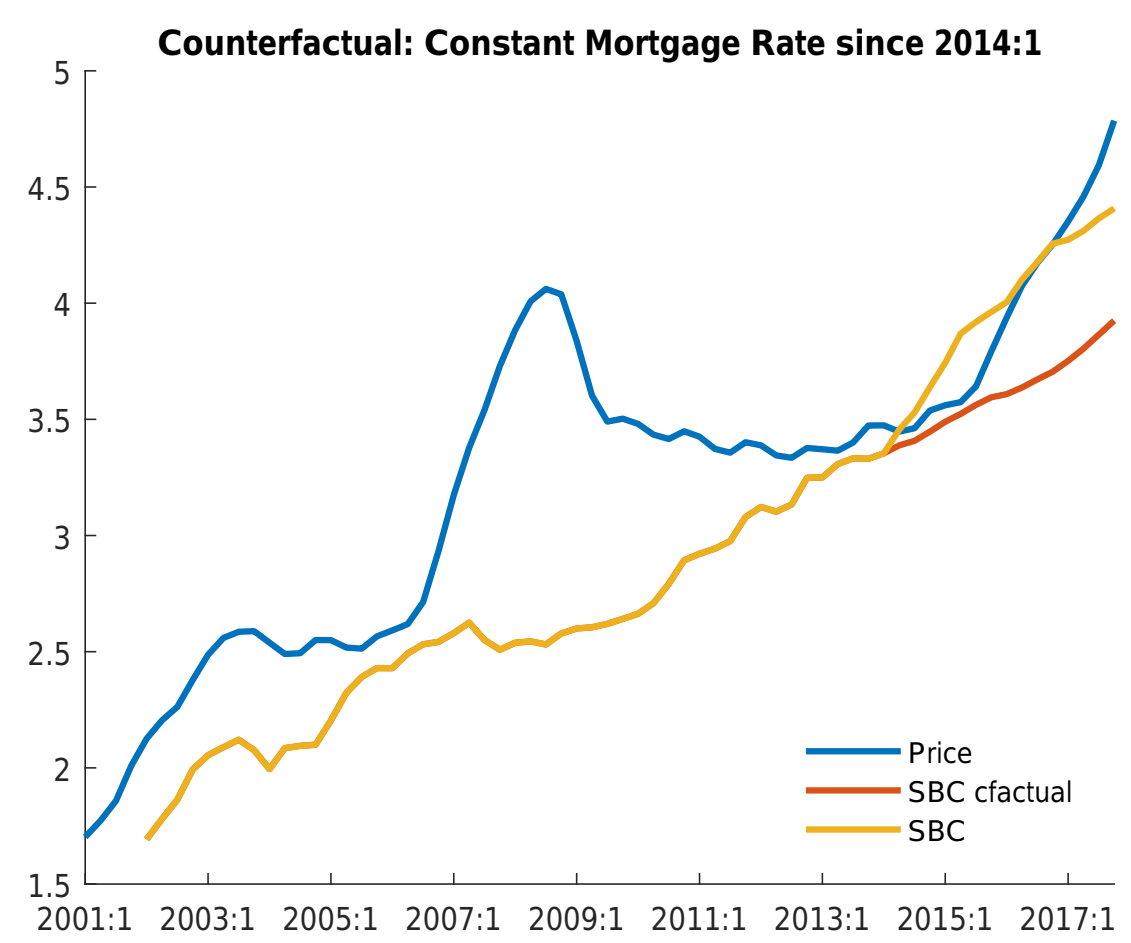

rate and on household incomes fixed by the borrowing-constraint hypothesis, the estimated intercept would scale the 'attainable' house prices upwards to make the residual average be zero.

Counterfactual Estimate To better understand the dynamics of attainable house prices, we can estimate the effects of income and interest rates. To illustrate the role of mortgage rates on attainable house prices, Fig. 4 depicts the change in the attainable apartment price over the period 2014Q1 to 2017Q4 due to an alternative path for mortgage interest rates. The alternative path assumes that mortgage rates remained at their 2014Q1 level and did not decline any further.

The framework suggests that the decline of the mortgage rate from 3.42 percent to 2.3 percent (112 basis points) could have led to attainable house prices being higher by 15 percent, or close to a half-million CZK. This is roughly one year of nominal income for the average household in Prague - not a negligible role for the interest rate channel. Note that mortgage rates were decreasing as the short-run policy rates stayed at their effective zero lower bond, 
Figure 5. Income and Interest Rate Effects

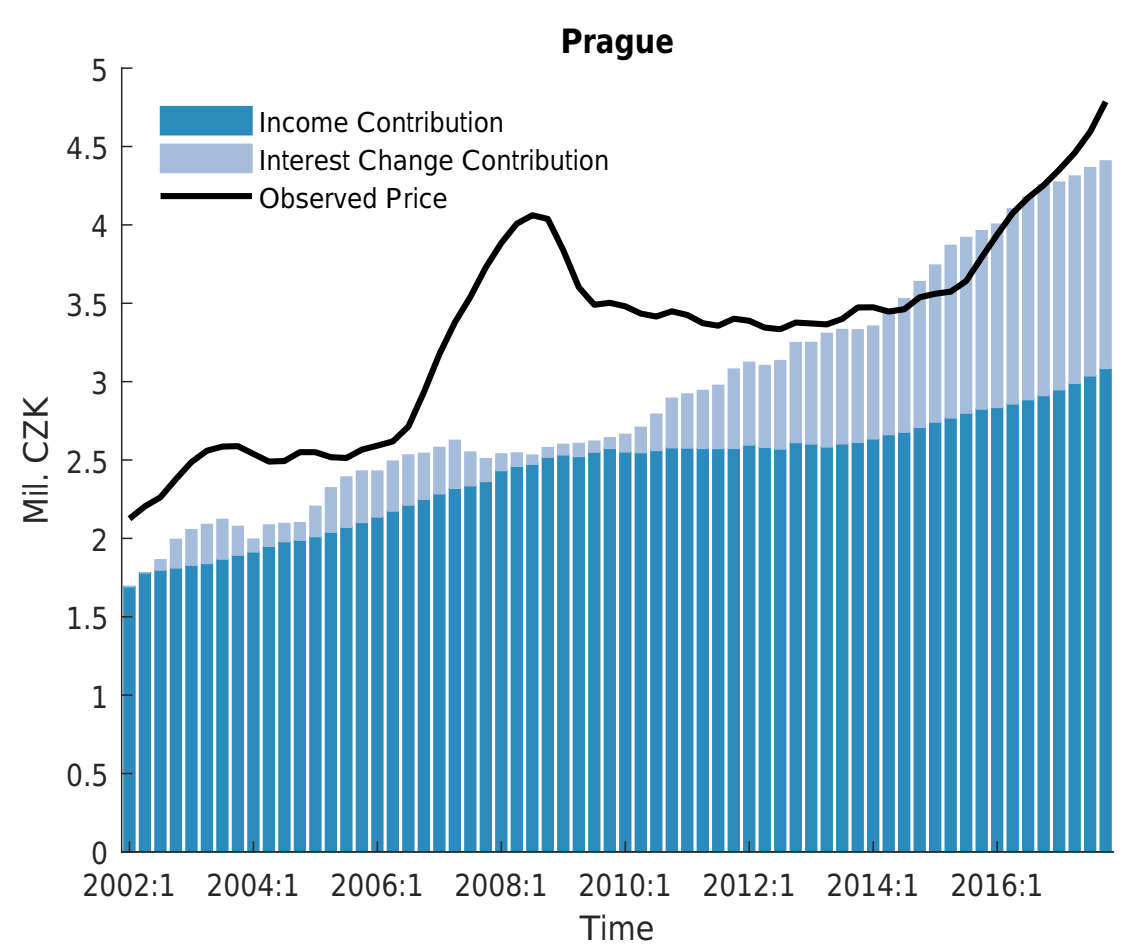

Note: The interest rate contribution due to the difference from the 2002Q2 level.

with the Czech National Bank supporting economic growth using foreign-exchange-rate interventions to weaken Koruna and thereby ease monetary conditions.

To fully account for the dynamics of mortgage interest rates, Fig. 5 uses the SBC formula to decompose the estimated attainable price in Prague into the contribution of household income and interest rates. The interest rate contribution quantifies the contribution of interest rates due to their deviation from the level in 2002Q2, not from their zero level. The decline of mortgage interest rates have contributed to sizeable increase in estimated attainable house prices.

Sensitivity Analysis To assess the significance of changing the key parameter of the borrowingcapacity approach, the debt-service-to-income ratio, $\alpha$, Figure 6 depicts the static borrowing capacity for values of $\alpha$ at $30 \%$, the baseline $35 \%, 40 \%$ and the recently adopted prudential limit of $45 \% .{ }^{17}$ The differences are sizeable. Indeed, the debt-service-to-income, $\alpha$, is the

\footnotetext{
${ }^{17}$ Effective from October 2018, the Czech National Bank issued a recommendation to commercial banks that the initial debt-service-to-income ratio, $\alpha$, should not be higher than $45 \%$.
} 
Figure 6. Sensitivity Analysis with Respect to $\alpha$

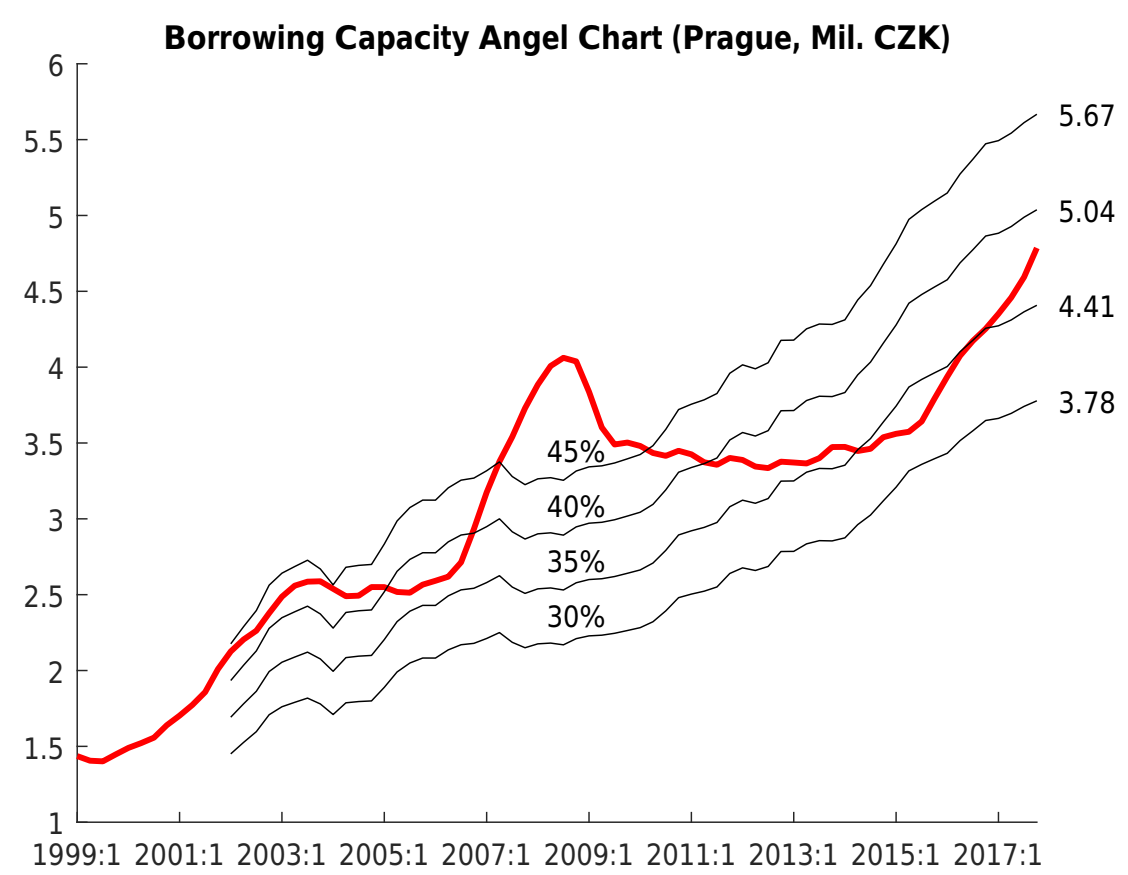

most crucial parameter determining the dynamics of house prices. The amount of housing the household can borrow for by devoting a grand total of 45 percent of their income to mortgage payments is higher by 50 percent than in the case of allocating 'just' 30 percent. This is an obvious implication of the formula (4) with $\alpha$ being 50 percent higher.

\section{Intrinsic-Value Approach}

The 'fair value' estimate of an average-size apartment in Prague is compared to observed prices in Figure 7. The valuation results indicate that the intrinsic value is increasing, driven mainly by the robust increase the household nominal income. It also suggests three periods of overvaluation with respect to fundamentals: roughly $10 \%$ over-valuation in 2003 , the historically-highest over-valuation in 2008 by $30 \%$, and the most recent period that started at the end of 2015 of roughly $15 \%$ in 2017.

By mid 2018, house prices growth has strongly outpaced the increase in nominal household income against a background of almost unchanged mortgage rates. Property prices have been a front-page topic of the Czech newspapers and journals for most of 2017 and 2018 and house 
Figure 7. Average Intrinsic Value vs. Observed Prices

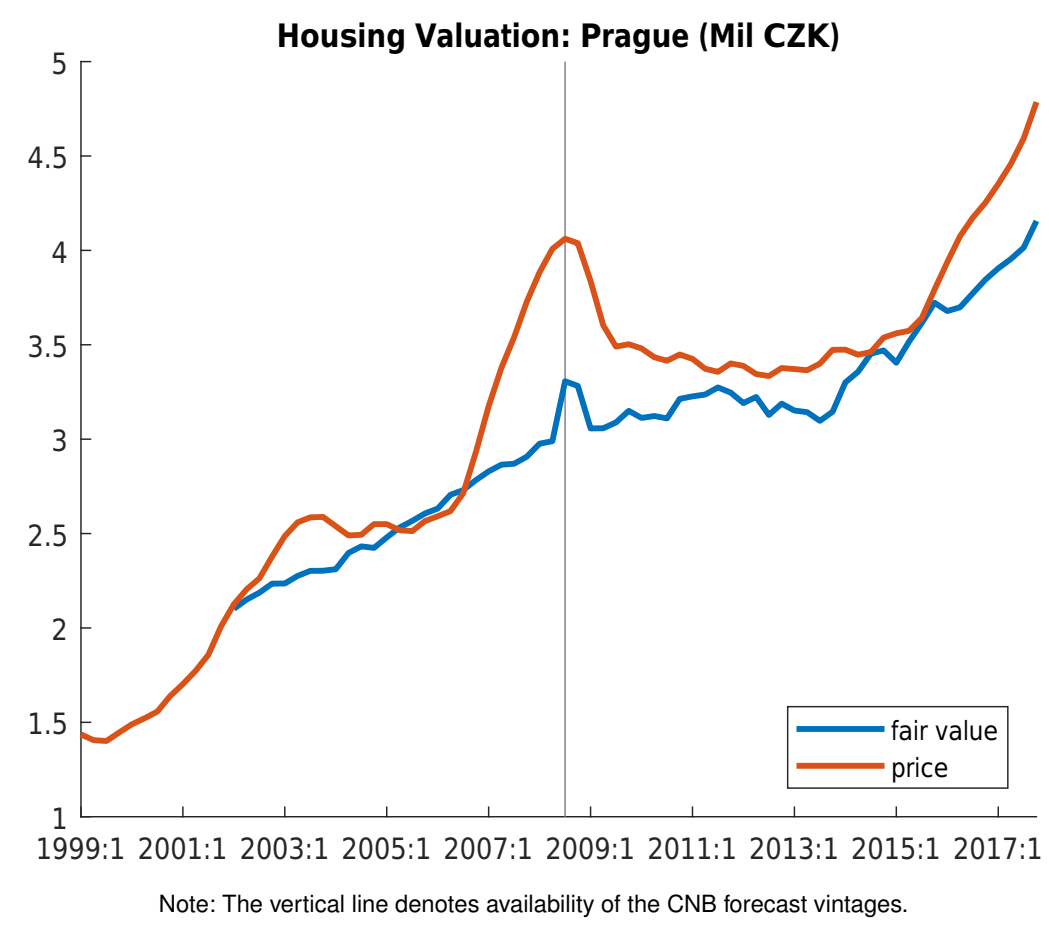

prices have been discussed at family dinners and have occupied the minds and meetings of central bankers.

Similar to the results of the static borrowing-capacity approach, the outcome of the intrinsicvalue approach is that 'attainable house prices' seem to form essentially a lower bound for the market price for realistic values of the model parameters. The market prices significantly deviate from the value implied by fundamentals at times, but only rarely do the observed market prices decline bellow this value. Our prudential and valuation indicators thus point to the same finding that average size of overvaluation is not zero but positive and seem to capture some general phenomenon. If this is correct, then standard regression models of house prices may overestimate the equilibrium house prices as they force the average of the residuals to be zero.

Due to the forward-looking nature of the intrinsic-value approach, we find it interesting to investigate the sensitivity of house prices with respect to the expected evolution of rents. Specifically, we will assume that the forecast of nominal household income growth after the CNB horizon is much more persistent in its convergence towards the steady-state growth and 


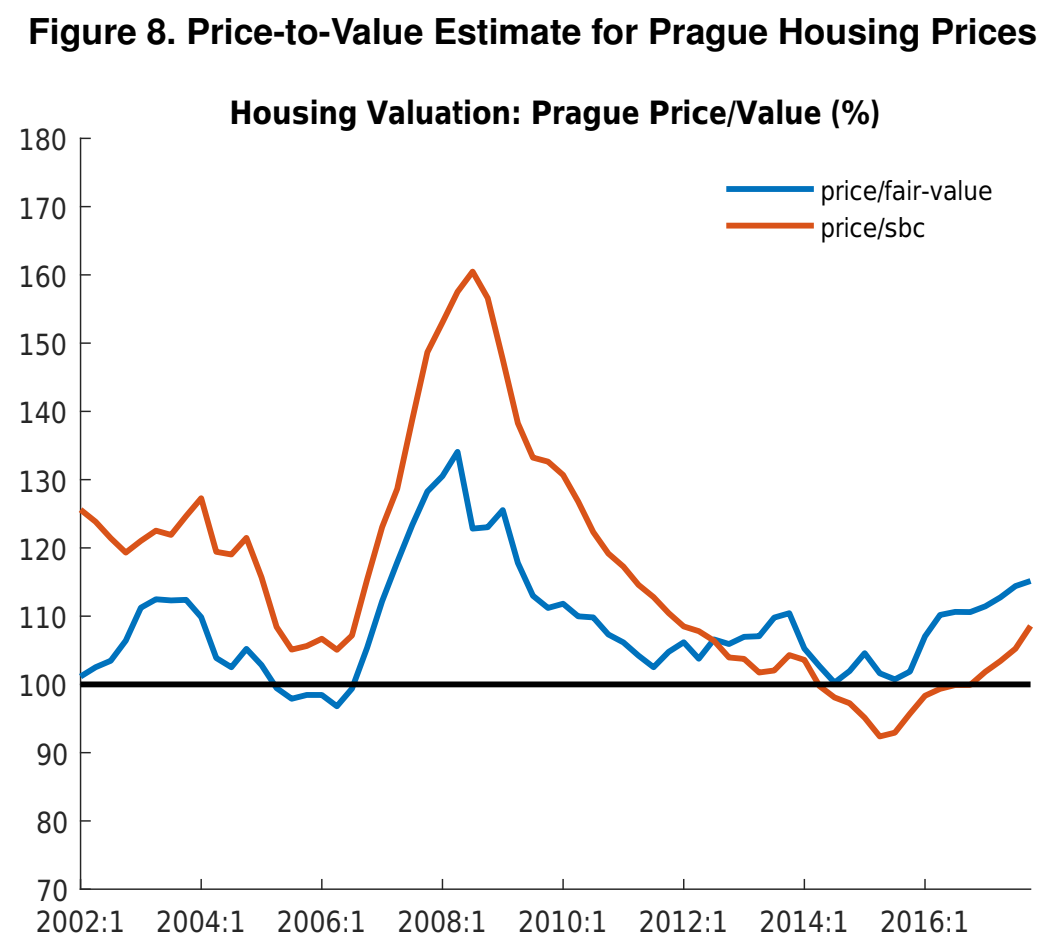

set $\rho=0.85 .{ }^{18}$ If, for all periods, we assume that the current growth rate becomes the permanent new growth rate, $\rho=1$, also the long-term growth in $\left[\left(1+g n_{t}\right) r e n t_{t+N \mid t}\right] /\left(i_{t}^{e}-g n_{t}\right)$ would change with enormous consequences for valuation levels.

As Figure 9 illustrates, overly optimistic income expectations lead to more volatile house valuations that follow the house prices dynamics more closely both in 2008 and 2015 onward. Given the uncertainty in the income outlook and the long-run nominal growth rate, the variation in observed house prices may result in overly optimistic expectations of medium- and long-term income growth rates. This confirms the well-known adage that 'value is in the eye of beholder'. However, this value proposition is accessible only to households who are not liquidity constrained, given the results for the static borrowing capacity approach.

Further, as indicated in the theory section, should an investor use static (steady-state) relationship to value housing, (7), the low interest rates and unusually high income growth would result in the investor overvaluing the property. Implicitly, the investors would assume that the low (or high) interest rates and high (low) income growth will last forever.

\footnotetext{
${ }^{18}$ The key point here is mostly to compare lower expected income growth persistence and higher income growth persistence, the value is mostly illustrative. The half-life of an $\operatorname{AR}(1)$ process with $\rho=0.85$ is 4.3 years, that is, after 4.3 years the current growth reduces its deviation from the long-run growth by half. The baseline persistence of $\rho=0.25$ is much smaller and it should be understood mainly in the context of annual frequency and the need to extend the CNB's medium-term forecast towards the long-run growth.
} 
Figure 9. Effects of Over-Optimistic Income Expectations

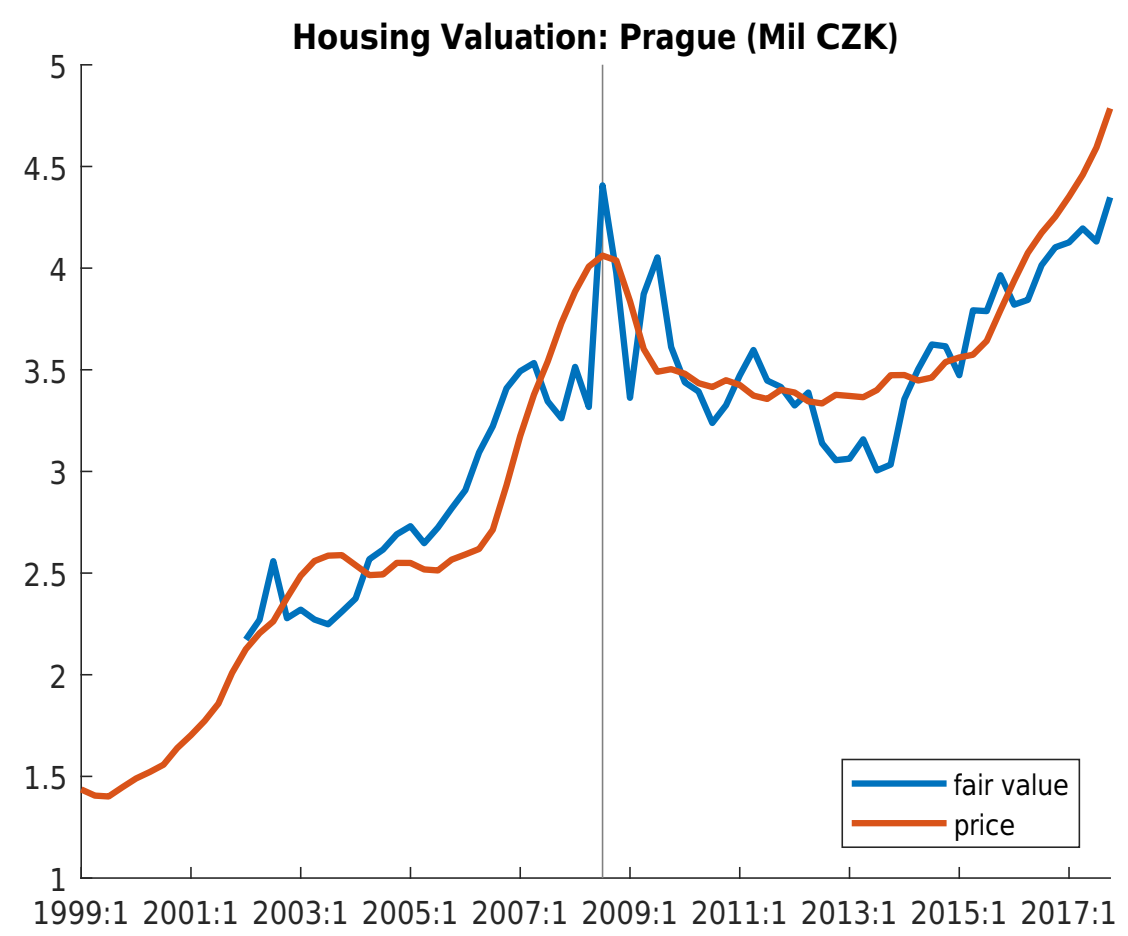

The dynamics of the intrinsic-value approach also react differently to changes in mortgage interest rates than does the borrowing-capacity approach. Under the static approach, households are assumed not to consider future dynamics of interest rates, only of the current mortgage rates. A decline in mortgage rates, even a temporary one, may relax their credit constraints significantly. Under the forward-looking investment approach, a decline in mortgage rates that is deemed short-lived may not lead to large re-assessment of the valuation as it effects on the net-present value will be limited.

\section{EXTENSIONS AND FURThER ANALYSiS}

We are working on several extensions of the present analysis. The analysis in this paper and the tools we introduced can be applied to other countries, the regions of a selected country, or particular cities. Another promising extension is the closer exploration of the valuation gaps that we obtain. In this paper, we ask what are the fair values or attainable prices of housing. However the question of why the observed prices decouple from fundamentals is left without explicit answer. Econometric analysis of these non-zero-mean gaps and the possible explanatory factors is a next logical step, after the asymmetric nature of these gaps is addressed. 
Reasons frequqntly associated with the observed prices moving away from fundamentals are the factors causing severe demand-supply mismatch. Factors ranging from demographics to local zoning rules, not-in-my-back-yardism, and supply constraints. Although a closer inspection of insufficient supply and supply-side constraints goes beyond the scope of this paper, we note that such analysis warrants some caution. In particular,the comparison of change in the number dwelling completions and households will not necessarily provide a clear proof of supply imbalance. This is because the observed data can suffer from reverse causality. Only the households who find and purchase a dwelling settle in and register in the city, thus entering the population statistics. This can make the completed dwellings and change in households comove together, while the market tightness remains. This has clear implications for the modelling framework and input variables used therein. See Figure 10 in the Appendix for co-movment of completed dwellings and estimated change in households in Prague.

Lastly, we embed the current analysis into a more general framework for assessment of prudential regulation on household and corporate credit and its sustainable evolution, see Andrle and Plašil (2019).

Figure 10. Prague: Completed Dwellings vs. Increase in Number of Households

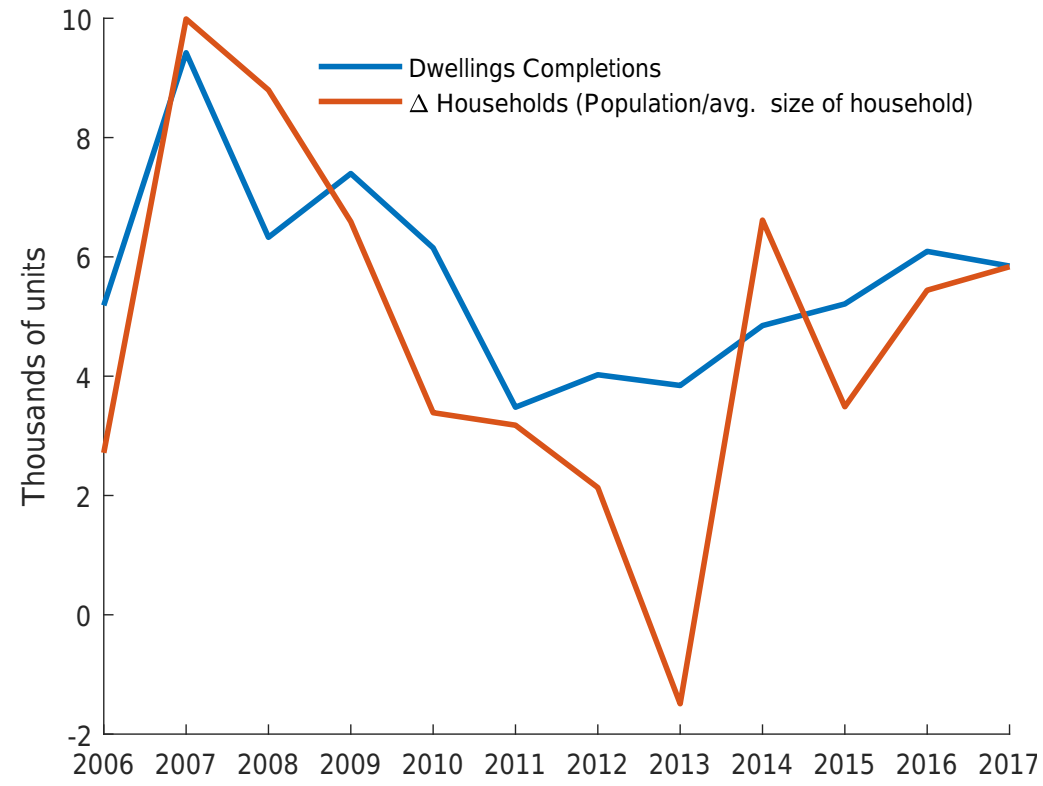




\section{Conclusion}

In this paper we have provided a simple prudential and valuation approach to assess observed house prices. Our approach is structural and suitable for analysis at both the macroeconomic level or at the level of individual household or property.

We suggest anchoring the house-prices analysis to the borrowing capacity of credit-constrained households or to the valuation of future expected net rental income of the real-estate asset. With the borrowing capacity approach we compute how much housing households can afford, given their income, saved down payment, market mortgage rates, and households' planned mortgage payment share of income. With the valuation approach, we project the market rental income for a given property using the household income dynamics, mortgage structure, and interest-reate outlook and value the property using the present value of the cash-flow adjusted for mortgage payments.

The proposed indicators are available in real time, do not require historical data for estimation, and do not suffer from revisions. They are also suitable for scenario and sensitivity analysis. The forward-looking indicators require estimates of the future path of household income (or rents) and interest rates. As most policy institutions and central banks create their own regular macroeconomic forecasts, the proposed indicators can easily relate to these forecasts and estimate valuations consistent with those official forecast.

To illustrate the use of the indicators, we applied the prudential and valuation measures to average house prices in Prague, the Czech Republic. We find that the average house prices were overvalued with respect to fundamentals by 10-15\% in 2017 and early 2018. In our view these estimates should be interpreted as rather conservative, as we use aggregated average data at the macroeconomic level. Going beyond aggregates, the prices of small apartments were rising much faster than the prices of larger, luxury apartments.

On a more conceptual level, our empirical analysis suggests that 'attainable house prices' seem to form essentially a lower bound for the market price in Prague. Such a result implies that the average size of overvaluation may not sum to zero, but rather be positive throughout the cycle. If there are more overvaluations than under-valuations, this has implications for the econometric modelling of house prices as it could lead to overestimation of the equilibrium house prices. 


\section{REFERENCES}

Andrle, M., and M. Plašil, 2019, "A Framework for Assessing the Effects of Macroprudential Policies," mimeo, Czech National Bank, International Monetary Fund.

Damodaran, A., 2012, Investment Valuation: Tools and Techniques for Determining the Value of Any Asset, Third Edition (New York: John Wiley \& Sons, Inc.).

ECB, 2011, "Box 3: Tools for Detecting a Possible Misalignment of Residential Property Prices From Fundamentals,' Financial stability review, European Central Bank, Frankfurt.

__ 2015, "Box 3: A Model-Based Valuation Metric for Residential Property Markets," Financial stability review, European Central Bank, Frankfurt.

Fox, R., and P. Tulip, 2014, “Is Housing Overvalued?” Research Discussion Paper RDP 201406, Reserve Bank of Australia, Sydney.

Geng, Nan, 2018, "Fundamental Drivers of House Prices in Advanced Economies," Working Paper 18/164, International Monetary Fund, Washington DC.

Hejlová, H., M. Hlaváček, and L. Komárek, 2017, “A Comprehensive Method for House Price Sustainability Assessment in the Czech Republic," Prague Economic Papers, Vol. 26, No. 3, pp. 269-285.

Hejlová, H., L. Holub, and M. Plašil, 2018, “The introduction and calibration of macroprudential tools targeted at residential real estate exposures in the Czech Republic," in $C N B$ Financial Stability Report 2017/2018, Occasional Publications - Chapters in Edited Volumes, chap. 0, pp. 126-135 (Czech National Bank, Research Department).

Himmelberg, Ch., Ch. Mayer, and T. Sinai, 2005, "Assessing High House Prices: Bubbles, Fundamentals and Misperceptions,' Journal of Economic Perspectives, Vol. 19, No. 4 (Fall), pp. 67-92.

Iacoviello, M., and S. Neri, 2010, "Housing Market Spillovers: Evidence from an Estimated DSGE Model," American Economic Review, , No. April, pp. 125-164.

Igan, Deniz, and Prakash Loungani, 2012, "Global Housing Cycles," Working Paper WP/12/217, International Monetary Fund, Washington, D.C.

McCarthy, J., and R.W. Peach, 2004, “Are Home Prices the Next "Bubble”?" Federal Reserve Bank of New York, Economic Policy Review, , No. December, pp. 1-17.

OECD, 2005, "Recent House Price Developments: The Role of Fundamentals," OECD Economic Outlook No. 78, Organization for Economic Cooperation and Development, Paris.

Philiponnet, N., and A. Turrini, 2017, “Assessing House Price Developments in the EU,' Discussion Paper 048/2017, European Comission, Brussels.

Silver, M., 2012, “Why House Prices Indexes Differ: Measurement and Analysis,” Working Paper WP/12/125, International Monetary Fund, Washington, D.C. 
Warisse, Ch., 2017, "Analysis of the Developments in Residential Property Prices: Is the Belgian Market Overvalued,' Economic Review 4, National Bank of Belgium (NBB), Brussells. 


\section{Appendix A. Why We Do Not Use a Regression Model}

We would like to explain in more detail why we seek to provide an alternative analytical approach to a large part of the literature about house prices that relies on time-series or paneldata econometrics.

Our main reason for not using regression analysis is the desire to have a more structural model, with a few clearly interpretable parameters and inputs, like household income, mortgage rates, loan-to-value ratio, without entering the full complexity of general-equilibrium modeling.

Other reasons for not relying on regression analysis is that the regression models are often only vaguely motivated by economic theory in terms of their structure and the choice of variables. Variables often included in the regression model are income, multiple interest rates (long, short), stock of credit, stock market indicators, demographic variables, etc. But if both (new) credit and income are included, implicitly the loan-to-value ratio is lurking behind without the analyst being able to use it explicitly for scenario analysis, for instance. Moreover, explanatory variables usually capture both fundamental and transitory factors making it difficult to distinguish between the two in the analysis.

Econometric models also require a significant amount of historical data, preferably over multiple business cycles or financial cycles to avoid the parameter instability. With short data sample, the coefficients can be severely biased, without using theory restrictions. Also, given the long-run trends in nominal and real interest rates, it is not trivial to get theory-consistent values and signs of key coefficients without tight priors. Further, regression models are static in their nature and intrinsically backward-looking, unlike the dynamic borrowing capacity or the present-value computations we try to propose. We believe that the value of an asset should be mainly determined by the current and future conditions not by the past.

We provide a simple illustration of these problems using the data for Prague. We estimate a simple co-integrating relationship using the same variables we use in the borrowing capacity and the intrinsic value approach, i.e. household income and the mortgage rates. We estimate the following relationship: ${ }^{19}$

$$
\log P H_{t}=\alpha_{0}+\alpha_{1} \log Y_{t}+\alpha_{2}\left(1 / i_{t}\right)+\varepsilon_{t}
$$

19 Alternative specifications of the interest-rate term do not matter for the stability considerations or fit. Note that in case of growth-rate specifications, the intercept should be restricted to zero to avoid a deterministic trend in house prices in excess of value implied by fundamentals. 
in a sample running from 2002:Q1 to 2017:Q4.

The estimated relationship does not have stable coefficients throughout the sample and the fitted value of house prices for an average apartment changes as the coefficients get re-estimated. Further, under no transformation of the interest rate term do the unconstrained coefficients follow a sign implied by the theory. Coefficient instability severely limits the scope of sensitivity and counterfactual scenarios.

Fig. 11 illustrates the magnitude of over- and under-valuation as implied by the estimated set of three regression coefficients. Clearly, as the sample accrues, the ex-post views differ from real-time views. Specifically, the most recent period, the period of most interest, clearly is affected by coefficient instability to a great extent.

Another interesting aspect of standard regression-based estimates is that a linear regression model with an intercept (the 'constant') has by construction residuals averaging to zero. The model thus by construction flags periods of under-valuation as well as periods of over-valuation, in contrast to both approaches in this paper which suggest that in Prague the periods of overvaluation and 'fair' valuation are most common, without house prices getting undervalued much. Further, in models specified in growth-rates only, the intercept itself is problematic, as it introduces an autonomous drift in house prices that exceeds the dynamics of fundamentals.

It is true that our estimated model is rudimentary. However, the used variables provided enough insight with the borrowing capacity and intrinsic value approaches and adding more variables to the model, given the sample size, would likely over-parameterize the model and thus require more advanced shrinkage estimation with careful cross-validation to avoid over-fitting. In addition, our aim is not to come up with a forecasting model for house prices but to find an 'equilibrium' towards which house prices will revert over time. ${ }^{20}$

\footnotetext{
${ }^{20}$ A detailed analysis by Hejlová, Hlaváček, and Komárek (2017) of the Czech house prices with much richer model also points to instability of the estimated coefficients.
} 
Figure 11. Co-Integration Estimates: Results
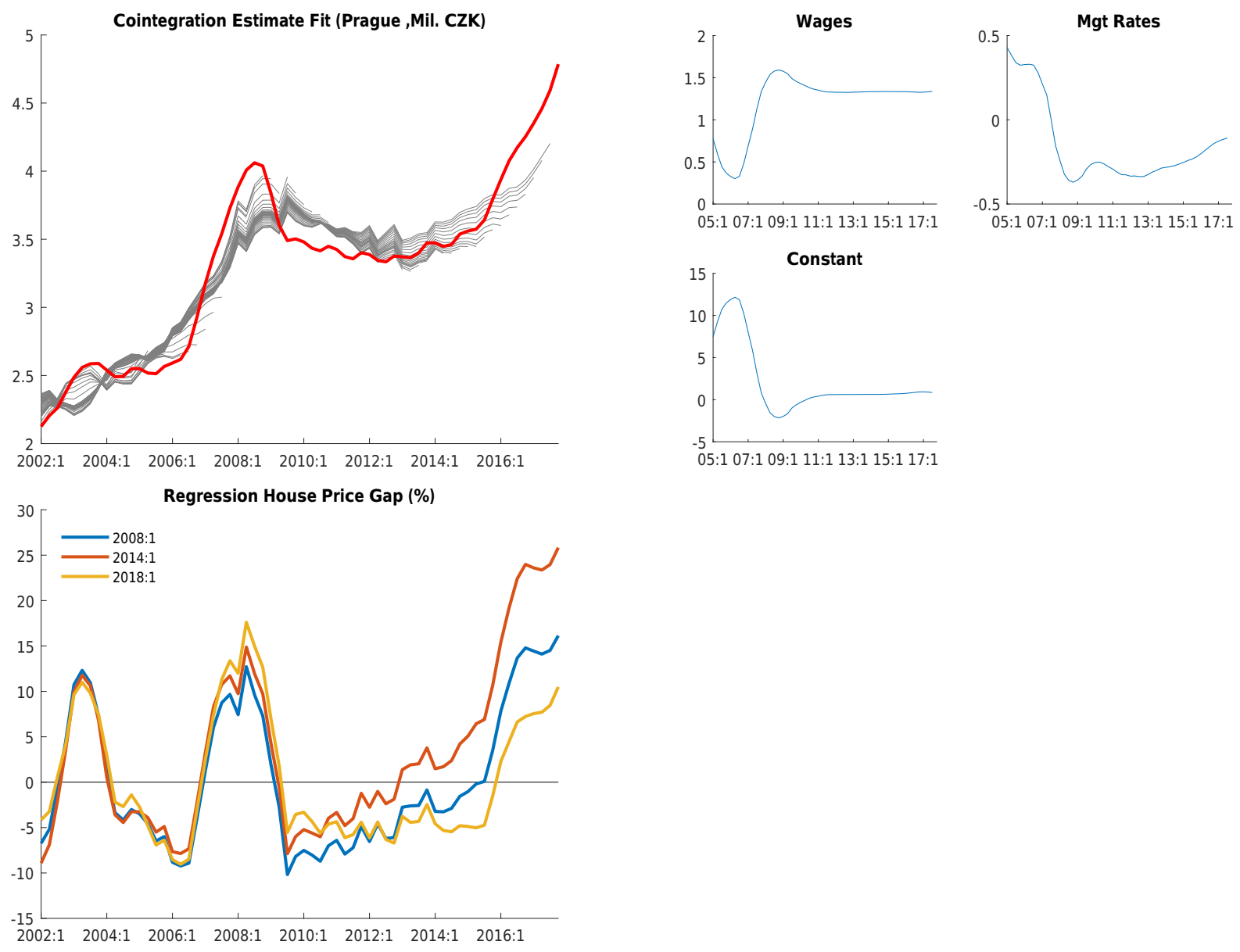

CInternational Monetary Fund. Not for Redistribution 


\section{Appendix B. Building Prudential Scenarios AND COUNTERFACTUALS WiTh THE SBC APPROACH}

As alluded to in the main body of the paper, for certain policy simulations or counterfactual simulations care must be taken when using the static borrowing capacity approach. One important consideration is whether the counterfactual scenario should capture the short-run, medium-run, or the long-run effects. For each of the horizons we can assume some variables as fixed or at least slow-moving. Another important consideration is what prudential constraints are binding or what is their distance from the bound. ${ }^{21}$ See Andrle and Plašil (2019) for details how to use the approach proposed for building policy scenarios to assess prudential policies on credit and house prices.

For instance, after a decline in mortgage interest rates, which relaxes the borrowing constraint and for unchanged DSTI ratio, $\alpha$, the amount of loan available for households increases. The attainable prices may increase thanks to lower interest rates and potentially higher loan amounts (without the need of higher income) but the size of the increase in the short run depends on the behavior of the down payment and the distance from the loan-to-value ratio maximum, $\phi_{\max }$. If the down payment stays constant and $\phi<\phi_{\max }$, households can borrow more and-ceteris paribus-the warranted house prices are higher. The attainable prices correspond to $P H_{1}=L_{1}+D_{0}$, with $L_{1} \geq L_{0}$ and higher leverage until the constraint of the $L T V_{\max }$ becomes binding. If the loan-to-value ratio is at its regulatory maximum, $\phi=\phi_{\max }$ the lower mortgage interest rates won't allow households to borrow more unless the down payment increases, assuming that flexible house prices would immediately absorb the potential increase in the loan. Larger increase in house prices due to a decline in mortgage interest rates would occur if the down payment could increase and accommodate the higher mortgage loan while stabilizing the leverage.

It is thus clear that in the short term, the dynamics of the funds available for the down payment can become an important factor for assessing the effects of prudential policies. One way to see that is to recall the fundamental relationship

$$
P_{t}^{h} \times H_{t}=L_{t}+D_{t}, \quad \text { s.t. } \quad \alpha \leq \alpha_{\max }, \phi \leq \phi_{\max }
$$

where $L_{t}$ is the loan attainable by the household and $D_{t}$ is the available down payment.

\footnotetext{
${ }^{21}$ Alluding to short-term and long-term analysis and the distance to binding constraints may be reminiscent of traditional Keynesian/Neoclassical analysis with fixed wages and economic slack in the short run and flexible prices the economy on its potential output in the long run.
} 
In the main body of the paper, the assumption of binding debt-service-to-income ratio, $\alpha$ and binding loan-to-value ratio, $\phi$, was used to derive the baseline borrowing-capacity formula, with the implied down payment. This is realistic and the formula is valid for the observed average values $\alpha$ and $\phi$. Yet for some prudential scenarios the fundamental borrowing capacity relationship may be rewritten using explicit expression for the down payment:

$$
P_{t}^{h} \times H_{t}=\left[\frac{z_{t}\left(1-z_{t}^{N \times 12}\right)}{1-z_{t}}\right] \times \alpha Y_{t}+D_{t},
$$

for easier short-term analysis of the down payment and income dynamics.

We will illustrate that for the credit-constrained households, the down payment can be linked to their current income, $D_{t}=\kappa_{t} Y_{t}$, where $\kappa_{t}$ links the existing funds for down payment to household income. The attainable house pricing condition can then be always formulated as

$$
P_{t}^{h} \times S_{t}=\left[\frac{z_{t}\left(1-z_{t}^{N \times 12}\right)}{1-z_{t}}\right] \times \alpha Y_{t}+\kappa_{t} \times Y_{t} .
$$

At any point in time, the parameters $\alpha, \kappa$, or $L T V$ can be set or computed, depending on the scope of the analysis. However, they cannot be set independently. These quantities are closely related as

$$
\kappa_{t}=\frac{\left(1-L T V_{t}\right)}{L T V_{t}} \times \alpha_{t} \times f\left(z_{t}\right),
$$

where we have used the abbreviation, $f\left(z_{t}\right)$ for the interest rate term in (4).

Specifically, we can assume that the down payment of the household comes from accumulation of past savings from their income and a portion due to other wealth: $D_{t}=D_{t}^{Y}+D_{t}^{W}$. Making assumptions about the other sources of income can be hard on the macroeconomic level and will depend on the context of the scenario, so we set it to zero. The down payment due to accumulation of past saving is, however, an instructive exercise to make.

For credit-constrained households, a simple law of motion for the down payment can be specified for the analysis. Assume the household has been saving every year a portion of their income for a down payment, $s \times Y_{t}$, for a $R$ years in total. Assuming zero interest on their liquid saving for simplicity, their funds available for down payment in the current periods are thus 
given by:

$$
\begin{aligned}
D_{t} & =s \times Y_{t}+s \times Y_{t-1}+\ldots+s \times Y_{t-(R-1)} \\
& =s \times\left(Y_{t}+Y_{t} / g_{t}+\ldots+Y_{t} \prod_{i=0}^{(R-1)-1}\left(1 / g_{t-i}\right)\right),
\end{aligned}
$$

where $g_{t}$ stands for the gross income growth of the household in period, $t$. For actual computations time-varying growth rates are easy and important to use. But to help with the intuition, we can write down a steady-state version of the down payment to income ratio as

$$
D_{t}=s \times \frac{\left(1-g^{R}\right)}{(1-g) g^{R-1}} \times Y_{t},
$$

where the crucial dependence on $R$, the number of years of saving for the down payment, and on the income growth, $g$, should be noted. This simple relationship should help the intuition on linking the down payment to (past) levels of income.

The scenarios for bounds of the effects of prudential policies can be devised. However, it should be clear that a more comprehensive structural model is needed for more advanced tasks. The important assumption behind the SBC approach is that households are constrained and their perceived value of housing makes them willing buyers up to their debt-service-toincome and loan-to-value potential. 


\section{APPENDix C. TOOLBOX}

Together with this paper we are developing a user-friendly toolbox for house prices assessment. We have used the power of $R$ and Matlab computing environments. Using other platforms would be straightforward.

In addition, we have developed a user-friendly web-based graphic user interface (GUI) to improve the user experience. For instance, the interface developed in Shiny/R environment, see Fig. 12, can be used for flexible and interactive exploration of the borrowing capacity approach.

Figure 12. Interactive Interface to the Toolbox

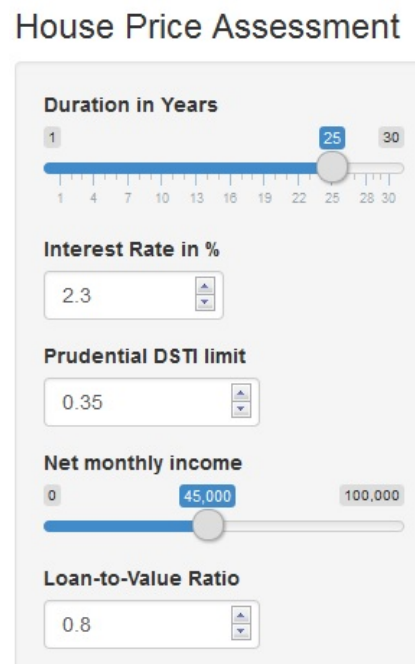

This application calculates three versions of the borrowing capacity

a) Static BC

b) Simple Look-Ahead BC

b) Look-Ahead BC with offset deposit

Price implied by the static borrowing capacity of households

4488600

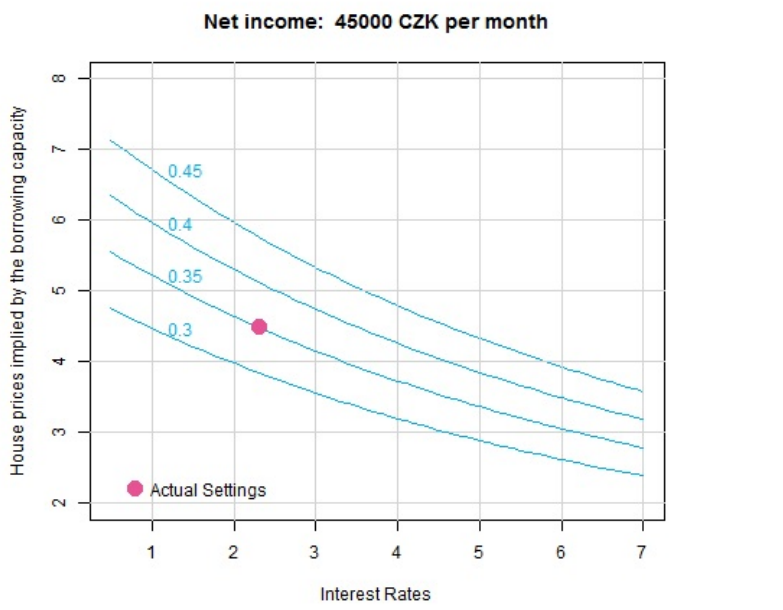

Source: Czech National Bank 